\title{
The Pharmacogenetics of Nicotine Dependence and Smoking Cessation Therapies
}

\author{
Martin M Zdanowicz ${ }^{1^{*}}$ and Patti W Adams ${ }^{2}$
}

${ }^{1}$ School of Nursing and Health Studies, University of Miami, Florida, USA

${ }^{2}$ South University School of Pharmacy, Georgia, USA

"Corresponding author: Martin M Zdanowicz, School of Nursing and Health Studies, University of Miami, 5030 Brunson Drive, Coral Gables, Florida 33146, USA, Tel: 305-284-4680; Fax: 305-284-2568; E-mail: mzdanowicz@miami.edu

Received date: July 25, 2014, Accepted date: August 21, 2014, Published date: August 29, 2014

Copyright: @ 2014 Zdanowicz MM, et al. This is an open-access article distributed under the terms of the Creative Commons Attribution License, which permits unrestricted use, distribution, and reproduction in any medium, provided the original author and source are credited.

\begin{abstract}
Tobacco-related diseases place a tremendous burden on health-care systems world-wide. Overall mortality for smokers is nearly three-fold higher than for similar non-smokers. This increased mortality results from higher rates of cancers, vascular disease or respiratory disease. Great strides have been made in recent years with regards to understanding the neurophysiologic pathways of nicotine addiction. While a number of pharmacologic interventions have been developed to aid patients in smoking cessation, overall success rates for long-term smoking abstinence remain disappointingly low.
\end{abstract}

A growing body of evidence suggests that a number of genetic factors might influence both the severity of an individual's nicotine addiction as well as the potential efficacy of various treatment modalities they might employ. The neurophysiology of nicotine addiction will be discussed along with genetic variants that can impact both nicotine pharmacodynamics and pharmacokinetics. The role that genetic variation plays in altering the efficacy of various smoking-cessation therapies will also be reviewed along with the potential therapeutic and economic benefits of utilizing genetic testing to optimize such drug therapies.

Keywords: Smoking cessation; Nicotine dependence; Pharmacogenomics

\section{Introduction}

Tobacco use in the United Stated exerts a tremendous burden each year on our health care system in terms of cost, morbidity and mortality. Based on current data, approximately 400,000 individuals die each year from cigarette smoking while another 8.6 million currently suffer from a smoking-related illness [1,2]. In terms of monetary burden, it is estimated that the annual cost of both public and private health care expenditures related to smoking is 96 billion dollars [2]. While the societal and individual benefits of smoking cessation are unequivocal, the effectiveness of various smoking cessation programs and therapies has been questionable at best. Current studies show that over $70 \%$ of current smoker's claim they want to quit smoking [3]. Over half of these will individuals who wish to quit smoking will actually do so for a short period of time. However, $80 \%$ of these individuals will eventually return to smoking. These statistics are a testament to the powerful addictive properties of nicotine [4].

Great strides have been made in recent years with regards to our understanding of nicotine addiction pathways in the brain. Numerous pharmacological and behavioral approaches have been utilized to aid patients in their quest to stop smoking. However, these interventions have been associated with considerable failure rates and significant inter-individual variability. As our understanding of nicotine addiction improves, a growing body of evidence indicates that genetics may play an important role in both the severity of an individual's nicotine addiction as well as in the variability of that individual's response to different smoking cessation agents. Genetic variants in nicotinic receptors, nicotine metabolizing enzymes, and other central pathways related to addiction and reward have been identified that may play a role in the extent of an individual's nicotine dependence. Numerous other genetic variants have likewise been identified that can alter an individual's response to various smoking cessation agents and thus impact their likelihood for successful treatment. The main goal of this article is to review the current state of knowledge regarding genetic factors that can impact both nicotine addiction as well as the effectiveness of various pharmacologic agents used for smoking cessation. The presentation begins with an overview of the neurophysiology of nicotine addiction. Genetic variants in the nicotine addiction and reward pathways that can impact an individual's addiction liability and chances for successful smoking cessation will be discussed. The second section will review the current state of knowledge related to the pharmacogenetics of nicotine replacement therapy and other smoking cessation agents. Discussion will also address the role of genetic testing in the choice of therapy, and the potential economic impact of pharmacogenetics on smoking cessation therapies.

\section{Neurophysiology of nicotine dependence}

Nicotine is a tertiary amine that exerts its effects on the nervous system by binding and activating nicotinic acetylcholine receptors (nAChRs) located at peripheral ganglia and in the central nervous system. Nicotine is readily absorbed into the bloodstream when administered by a variety of routes. When inhaled as a component of cigarette smoke, it enters the alveolar spaces of the lung and is absorbed across the respiratory epithelium to rapidly enter the bloodstream. Upon entering the cerebral circulation nicotine readily 
penetrates the blood brain barrier, thereby achieving central nervous system access. By this route of administration, a bolus of inhaled nicotine is delivered to the brain within seconds. As with other drugs of abuse, this rapid rate of entry into the brain is associated with the rush that occurs with cigarette smoking and contributes to the positive reinforcement of nicotine use [5-7].

The feelings of pleasure, mild euphoria, increased arousal, decreased fatigue, and relaxation that are associated with nicotine use are largely due to the nicotine-induced activation of the mesolimbic reward system. Chronic nicotine use causes changes in the mesolimbic reward system (neuroadaptations) that ultimately lead to tolerance and nicotine dependence. In the nicotine-dependent individual, after a period of abstinence from nicotine use, withdrawal symptoms occur. These symptoms may include irritability, anxiety, stress, inattention, depression, and insomnia. Cravings and withdrawal symptoms drive the urge for re-administration of nicotine. Thus, nicotine addiction and abuse develops due to a combination of the desire to experience the "rewarding" effects of nicotine use, neuroadaptations causing a requirement for higher doses of nicotine to experience those effects, and the desire to avoid the negative symptoms associated with withdrawal [7-10]. The molecular mechanisms of these pathways are discussed in the following sections.

Activation of reward pathways: The potential for addiction to nicotine stems from its actions on nAChRs associated with activation of the mesolimbic system of the brain $[7,11]$. The mesolimbic system is composed of a number of distinct brain regions connected by neural projections. Many of these neuronal connections are made by dopaminergic neurons. Increased dopamine (DA) secretion in the mesolimbic system is thought to be the primary mechanism for activating "reward pathways" of the brain.

Mesolimbic dopaminergic pathways involved in motivation and reward largely originate in the ventral tegmental area (VTA), which is located in the midbrain region of the brainstem (Figure 1). Projections of dopaminergic neurons extend from the VTA to other regions of the mesolimbic system involved in cognition, reward-motivated behavior, and emotional memory. These regions include the prefrontal cortex, the nucleus accumbens, the amygdala, and the hippocampus. Increased dopaminergic neurotransmission to the nucleus accumbens is particularly important for the perception of reward. A growing field of data from both animal and human studies indicates that dopaminergic neurotransmission from the VTA to the nucleus accumbens is increased by numerous drugs of abuse and represents a common pathway in addiction [12]

At concentrations achieved after smoking a cigarette, nicotine stimulates neurotransmission from dopaminergic neurons extending from the VTA to the nucleus accumbens $[7,8,13,14]$. This nicotineinduced increase in dopaminergic neurotransmission occurs primarily through an indirect mechanism involving changes in the secretions of glutamate and gamma-aminobutyric acid (GABA). These neurotransmitters contribute to the regulation of dopamine release from VTA neurons. The excitatory neurotransmitter glutamate promotes dopamine secretion primarily through activation of NMDA receptors on dopaminergic terminals. In contrast, the inhibitory neurotransmitter GABA has hyperpolarizing effects on dopaminergic neurons, thereby opposing dopamine secretion. Nicotine binds and activates nAChRs on glutamatergic and GABAergic neurons that synapse on VTA dopaminergic neurons. Initially, nAChR activation increases the secretion of both glutamate and GABA [15]. However, the nAChRs associated with GABAergic neurons are thought to quickly desensitize, leading to a net increase in dopamine secretion by VTA neurons due to the loss of the inhibitory effect of GABA [8,11,16-18].

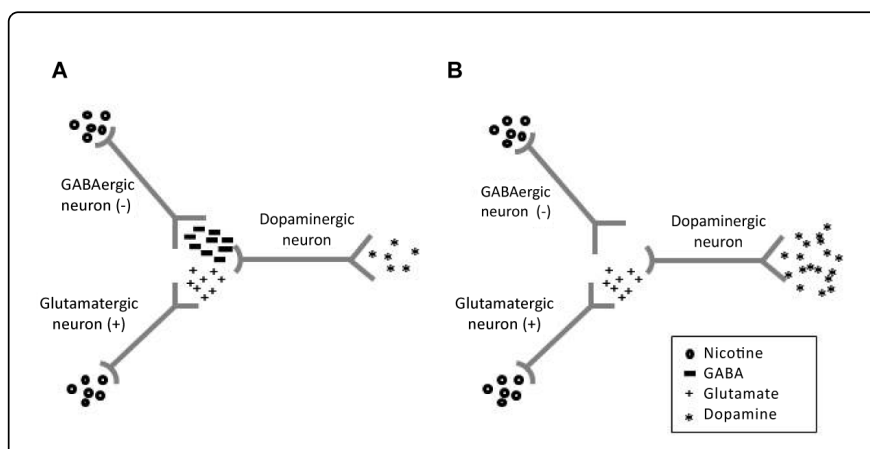

Figure 1: Schematic representation of nicotine effects on dopaminergic neurotransmission in the mesolimbic pathway. Nicotine indirectly regulates dopaminergic signaling in mesolimbic pathways. Nicotine activates nAChRs located on GABAergic and glutamatergic neurons that synapse on dopaminergic neurons in the VTA. GABA exerts hyperpolarizing effects (through GABA receptor activation), whereas glutamate exerts depolarizing effects (through NMDA receptor activation) on dopaminergic neurons. (A) Initially, increased secretion of both GABA and glutamate occur in the VTA in response to nicotine. (B) However, nAChRs located on GABAergic neurons are thought to rapidly desensitize, resulting in increased dopaminergic neurotransmission due to unopposed glutamate signaling in the VTA [11,15-17]. Differential desensitization rates of nAChRs on glutamatergic and GABAergic neurons may be due to differences in subunit composition of the receptors at the two locations [78].

In smokers, nicotine does not appear to be the only contributing factor to the activation of dopaminergic pathways of the brain's reward system. Inhibition of dopamine inactivation by monoamine oxidase enzymes may also be important $[18,19]$. Monoamine oxidase (MAO) enzymes occur in two major isoforms, MAO-A and MAO-B. While both isoforms catalyze the oxidative deamination of dopamine, the MAO-B isoform exhibits greater affinity for dopamine than the MAOA isoform. Thus, MAO-B is likely more important physiologically for the enzymatic inactivation of dopamine in the brain. In vitro and in vivo studies suggest that cigarette (tobacco) smoke contains nonnicotine components that increase dopamine levels in the mesolimbic system by reversible and irreversible inhibition of monoamine oxidase enzymes [20-23]. By blocking the degradation of dopamine in the brain, the presence of monoamine oxidase inhibitors in cigarette smoke would provide an additional mechanism to increase dopamine levels in the brain, further promoting the activation of the reward system and the development of addiction.

Neuroadaptation and dependence: Development of nicotine dependence begins with the binding of nicotine to specific nAChRs in the mesolimbic system of the brain. Nicotinic AChRs are ligand-gated cation channels that act as important regulators of neuronal excitability throughout the CNS, where they can be located at presynaptic, postsynaptic, and perisynaptic sites. Thus, nAChRs in the CNS regulate secretion of a wide range of neurotransmitters, including acetylcholine, dopamine, norepinephrine, serotonin, and glutamate, by affecting permeability of the neuronal membrane to $\mathrm{Na}^{+}, \mathrm{Ca}^{2+}$, and other cations [24]. In mesolimbic pathways, nAChRs enhance 
neurotransmission of both glutamatergic and GABAergic neurons, which have opposing effects on downstream dopamineregic neurons. However, due to the rapid desensitization of nAChRs associated with the inhibitory GABAergic neurons, the net effect is an increase in dopamine secretion in the reward pathways of the mesolimbic system.

The continued re-administration of nicotine (through smoking additional cigarettes) is likely an attempt to re-experience the rewarding effects of nicotine while avoiding withdrawal symptoms $[7,10]$. During the early stages of nicotine tolerance and addiction, smoking frequency is driven at the molecular level by the need to maintain specific populations of brain nAChRs in a saturated or nearsaturated state [25]. However, data from in vitro and in vivo studies indicate that the nicotine intake required to avoid withdrawal symptoms and achieve this level of nAChR saturation is also sufficient to induce receptor desensitization $[15,25,26]$. These observations suggest that for many smokers, specific populations of $\mathrm{nAChRs}$ are maintained in the saturated, desensitized state in an attempt to avoid withdrawal symptoms.

A subtype-specific increase in the density of nAChRs in brains of smokers is well documented [27-29]. This upregulation of nAChRs is likely a homeostatic response to the wide scale receptor desensitization that is thought to occur in the mesolimbic pathways. As more nAChRs are produced, greater nicotine intake is required to maintain the degree of receptor saturation needed for avoidance of withdrawal symptoms. Thus, upregulation of nAChRs is thought to be an important neuroadaptation in the development of nicotine dependence.

Withdrawal: In the nicotine-dependent patient, the absence of nicotine makes the previously acquired neuroadaptive changes inappropriate, resulting in a biochemical imbalance in the brain [30]. Thus, after a period of abstinence from nicotine, withdrawal symptoms develop. During nicotine withdrawal, decreased dopamine signaling to the nucleus accumbens has been observed and is considered an important trigger for the onset of withdrawal symptoms [14]. In contrast, dopamine signaling to the prefrontal cortex is increased during nicotine withdrawal. This pattern of dopamine signaling has similarly been observed following exposure of animals to anxiogenic or aversive stimuli [31,32], suggesting that anxiety associated with nicotine withdrawal may at least in part be affected by changes in mesolimbic and mesocortical dopaminergic signaling. Other affective symptoms of nicotine withdrawal that are also associated with such changes in dopamine signaling in the brain include anhedonia, irritability, difficulty concentrating, and tobacco craving. Thus, alterations in patterns of dopamine neurotransmission in the mesolimbic and mesocortical systems have important roles in mediating the withdrawal syndrome.

In summary, the likelihood of developing nicotine dependence is influenced by a number of factors. Nicotine dose and the duration and frequency of nicotine exposure to brain cells have important impacts on neuroadaptation and development of withdrawal symptoms. Therefore, genetic changes that impact nicotine-induced activation of any of the brain pathways involved in addiction can influence the likelihood of nicotine dependence in an individual. Likewise, genetic changes that increase or decrease the rate of nicotine metabolism and clearance from the body also affect an individual's risk of nicotine dependence.

\section{Pharmacogenomics of nicotine dependence}

Pharmacokinetics of nicotine: Due to the widespread use of nicotine-containing tobacco products, the pharmacokinetic properties of nicotine have been extensively studied $[26,33]$. Nicotine inhaled in cigarette smoke is rapidly absorbed across the respiratory membrane, producing a rapid rise in plasma nicotine concentration. Upon entering the circulation, it distributes to the tissues relatively quickly. In the average human, the distribution half-life of nicotine is approximately 8-20 minutes. Nicotine is metabolized by a number of pathways that are primarily housed in the liver, and nicotine and its metabolites are almost entirely excreted by the kidneys. Due to its rapid distribution and metabolism, the plasma half-life of nicotine is approximately two hours.

A number of nicotine metabolites are readily detected in urine, with only approximately $8-10 \%$ of absorbed nicotine excreted unchanged (Figure 2). The urinary metabolites serve as indicators of the relative importance of various pathways for nicotine metabolism. Cotinine is the major urinary metabolite, representing approximately $75 \%$ of total nicotine metabolites detected in urine [26,33]. Nicotine is converted to cotinine by a short reaction pathway involving two steps. In the first reaction, a cytochrome $\mathrm{P} 450$ (CYP450) enzyme converts nicotine to the nicotine imminium ion. The second reaction is catalyzed by cytoplasmic aldehyde oxidase and produces cotinine. Most of the cotinine that is produced is further metabolized to products that, like cotinine, are excreted in urine. The major CYP450 enzyme responsible for catalyzing the first reaction in the formation of cotinine is CYP2A6 $[34,35]$. In addition to the C-oxidation of nicotine, CYP2A6 also catalyzes a later reaction in the pathway in which cotinine is converted to trans-3'-hydroxycotinine. In vitro data suggest that CYP2A6 is responsible for greater than $80 \%$ of cotinine formation from nicotine, with CYP2B6 responsible for most of the remaining cotinine formation [35]. In individuals producing functional CYP2A6 enzymes, other CYP450 enzymes are likely to have only minor roles in the metabolism of nicotine. However, cotinine formation by other CYP450 enzymes, such as CYP2B6, may become more important in the absence of a fully functional CYP2A6 enzyme [36].

Based on the urinary nicotine metabolite profile, other pathways of nicotine metabolism play relatively minor roles in most individuals $[26,33]$. After cotinine, the next most abundant primary metabolites of nicotine are nicotine $N$-oxide, which composes $4-7 \%$ of total nicotine urinary metabolites, and (S)-nicotine- $N$ - $\beta$-glucuronide, which composes $3-5 \%$ of nicotine urinary metabolites (Figure 2). Nicotine $N$-oxide is formed by the $N$-oxidation of the pyrrolidine ring of nicotine, a reaction catalyzed by flavin-containing monooxygenase 3 (FMO3). UGT enzymes catalyze the $N$-glucuronidation of nicotine to produce (S)-nicotine- $N$ - $\beta$-glucuronide. Other primary metabolites of nicotine each compose $2 \%$ or less of total urinary metabolites of nicotine and are not considered to be major pathways for the metabolism and inactivation of nicotine in humans.

Polymorphisms affecting nicotine pharmacokinetics: The pharmacokinetic parameters of nicotine allow cigarette smokers fine control over the nicotine-mediated effects that they experience $[10,37]$. Inhaled nicotine is rapidly absorbed to the bloodstream. The short plasma half-life of nicotine reflects its rapid distribution, metabolism, and elimination. Despite the short plasma half-life, plasma levels of nicotine can rise throughout the day, especially in individuals who smoke one or more cigarettes per hour. By altering the pattern and frequency of inhalations and the number of cigarettes smoked, smokers can titrate plasma nicotine concentrations with relative 
precision to produce the desired effects. Anything that alters the pharmacokinetic parameters of inhaled nicotine is likely to affect smoking behavior as well as the likelihood for nicotine addiction in that individual $[6,38,39]$.

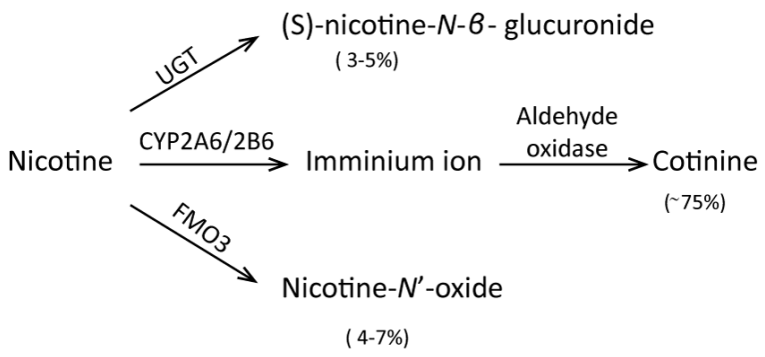

Figure 2: Important pathways for nicotine metabolism in humans. The majority of nicotine is converted to cotinine, which composes approximately $75 \%$ of the total urinary metabolites of nicotine $[6,27]$. Cotinine is produced by a two-step process catalyzed by a CYP450 enzyme and cytosolic aldehyde oxidase. CYP2A6 is the major CYP450 enzyme catalyzing the first reaction, with about $80 \%$ of total cotinine formation dependent on the activity of this enzyme. CYP2B6 has a minor role in catalyzing the first reaction in cotinine formation, but enzyme can assume a larger role in individuals with deficiencies in CYP2A6 activity. Other pathways contributing to nicotine metabolism include the $\mathrm{N}$-oxidation of nicotine by flavin-containing monooxygenase 3 (FMO3) and glucuronidation of nicotine by UDP-glucuronosyltransferases (UGT). Other pathways of nicotine metabolism have minor roles, each contributing to the formation of less than $2 \%$ of the total urinary metabolites of nicotine. About $8-10 \%$ of nicotine is excreted in the urine unchanged.

The rate at which nicotine is metabolized can influence smoking behavior and the risk of nicotine dependence [6,40-42]. Individuals with slower nicotine metabolism exhibit prolonged systemic exposure to nicotine as compared to those with normal metabolism [43]. Thus, slower nicotine elimination would be expected to reduce the frequency and intensity of withdrawal symptoms by decreasing the rate at which nicotine receptors in the brain become unoccupied. In support of this, slow metabolizers have been demonstrated to smoke fewer cigarettes than those with intermediate or "normal" levels of nicotine metabolism [39,42,44-47]. In a study by Pianezza and colleagues, individuals exhibiting slow nicotine metabolism were more common in the "never nicotine-dependent group" than in the "nicotine dependent group," suggesting that individuals who metabolize nicotine slowly may be less likely to become nicotine-dependent [42] In contrast, individuals who exhibit more rapid nicotine metabolism require greater nicotine intake to experience and maintain the effects of nicotine and avoid withdrawal effects [48]. This is supported by studies showing individuals with rapid nicotine metabolism smoke more cigarettes or smoke more intensely (e.g. depth of inhalation) than subjects with normal rates of nicotine metabolism $[39,40]$.

The CYP2A6 enzyme, which catalyzes the major metabolic pathway for nicotine, exhibits a high degree of genetic variation among humans. Nearly 100 polymorphisms of the human CYP2A6 gene have been described (indexed at www.cypallels.ki.se). At least 20 of these have been reported to be associated with altered rates of nicotine metabolism (Table 1) $[27,48,49]$. Individuals who express CYP2A6 variants with increased activity are described as "rapid metabolizers" of nicotine, while those expressing CYP2A6 variants with reduced activity are described as "slow metabolizers."

The CYP2A6 gene (CYP2A6) is organized into 9 exons and occupies a $6 \mathrm{~kb}$ region on the long arm of chromosome 19 (19q13.2). $C Y P 2 A 6$ is located within a $500 \mathrm{~kb} C Y P 2$ family gene cluster that includes $C Y P 2 A 7$ (with which $C Y P 2 A 6$ shares the greatest homology) and $C Y P 2 A 13[48,49]$. The CYP2A6 allele that is considered to have "normal" enzymatic activity is $C Y P 2 A 6^{*} 1 A$ [50]. A number of polymorphisms have been identified, many of which were formed through various crossover events with $C Y P 2 A 7$. Some $C Y P 2 A 6$ polymorphisms result in changes in the coding sequence, affecting the intrinsic activity of the enzyme itself [51-55]. However, a number of CYP2A6 polymorphisms have been identified that affect total CYP2A6 activity in the cell by influencing the enzyme level present in cells rather than its intrinsic activity. This can occur when the polymorphism affects mRNA and protein levels in the cell by altering expression rates or stability of these molecules. For example, altering promoter activity $[56,57]$ or gene copy number $[40,58]$ can change the total level of CYP2A6 activity in a cell by changing the total amount of enzyme made by the cell. Likewise, at least one polymorphism that is speculated to affect mRNA stability has been documented [59-61]. Polymorphisms of $C Y P 2 A 6$ also include those in which expression is altogether absent due to all or part (e.g. $C Y P 2 A 6^{\star} 4$ variants) of a gene being deleted [49].

Like $C Y P 2 A 6$, the gene encoding CYP2B6 ( $C Y P 2 B 6$ ) exhibits a high degree of variation in humans. Over 30 polymorphisms in the $C Y P 2 B 6$ gene have been described, with in vitro or in vivo data suggesting alterations in enzyme level or enzyme activity for at least 19 of these (www.cypalleles.ki.se). However, studies evaluating functional effects of $C Y P 2 B 6$ polymorphisms indicate that $C Y P 2 B 6$ genotype does not significantly affect nicotine C-oxidation in humans with fully functional $C Y P 2 A 6[62,63]$. Data from these studies are consistent with older studies reporting that CYP2B6 has only a minor role in nicotine metabolism [34-36]. While current data indicate that CYP2B6 genotype does not significantly affect nicotine metabolism in most humans, these studies have not examined CYP2B6 genotype effects in individuals with impaired CYP2A6 function. However, evidence does exist that CYP2B6 genotype may influence patient success rates in response to certain smoking cessation therapies, as discussed below $[64,65]$. Therefore, the effect of CYP2B6 genotype on susceptibility to nicotine dependence and likely success in smoking cessation needs further examination.

Genetic variation in other enzymes that normally represent minor pathways in nicotine metabolism can impact nicotine inactivation and clearance, particularly in the absence of a fully functional $C Y P 2 A 6$ allele. Comparisons of urinary nicotine metabolite profiles in patients with wild-type $C Y P 2 A 6$ to those with nonfunctional $C Y P 2 A 6$ alleles have been used to demonstrate shifts in the relative importance of different metabolic pathways. This type of analysis has been used to show increased formation of nicotine $\mathrm{N}$-oxide and nicotine $\mathrm{N}$ glucuronide in subjects homozygous for the CYP2A6 deletion allele (e.g. $C Y P 2 A 6^{*} 4 /^{*} 4$ ) versus those homozygous for the wild type allele (e.g. $C Y P 2 A 6^{*} 1 A{ }^{*} 1 A$ ) [66]. Changes were accompanied by more than a 15 -fold decrease in cotinine formation. These data suggest that FMO- and UGT-mediated metabolic pathways can become upregulated to compensate for the absence of CYP2A6 function. 
Citation: Zdanowicz MM, Adams PW (2014) The Pharmacogenetics of Nicotine Dependence and Smoking Cessation Therapies. J Pharmacogenomics Pharmacoproteomics 5: 138. doi:10.4172/2153-0645.1000138

Page 5 of 20

\begin{tabular}{|c|c|c|c|}
\hline Allele & $\begin{array}{l}\text { Nucleotide or } \\
\text { Structural Change }\end{array}$ & $\begin{array}{l}\text { Effect on Total CYP2A6 } \\
\text { Activity }\end{array}$ & Reference \\
\hline$C Y P 2 A 6 * 1 A$ & Wild type & Normal & {$[50]$} \\
\hline CYP $2 A 6^{*} 1 \times 2$ & Gene duplication (increased copy number) ${ }^{1}$ & Increased & {$[40,58]$} \\
\hline$C Y P 2 A 6 * 1 B$ & Gene conversion in 3'UTR (increased mRNA stability) ${ }^{2}$ & Increased & {$[59,61,206,207]$} \\
\hline$C Y P 2 A 6^{*} 1 H$ & SNP in 5' flanking region decreases promoter activity (expression) & Decreased & [57] \\
\hline CYP2A6*2 & SNP in exon 3 (produces L160H mutated protein) & No activity & {$[50,51,208]$} \\
\hline CYP2A6*3 & Gene conversions in exons $3,6,8$ (CYP2A6/CYP2A7 hybrid) (very rare) & No activity & [209] \\
\hline CYP2A6*4 & $\begin{array}{l}\text { Gene deletions resulting from unequal crossover events between CYP2A6 and } \\
\text { CYP } 2 A 7^{3}\end{array}$ & No activity & {$[60,210-214]$} \\
\hline CYP2A6*5 & $\begin{array}{l}\text { SNP in exon } 9 \text { (produces G479V mutated protein with reduced enzyme levels) and } \\
\text { gene conversion in 3'-UTR }{ }^{4}\end{array}$ & Decreased & {$[60]$} \\
\hline CYP2A6*6 & SNP in exon 3 (produces R128Q mutated protein with decreased intrinsic activity) & Decreased & [52] \\
\hline CYP2A6*7 & SNP in exon 9 (produces 1471T mutated protein with decreased intrinsic activity) & Decreased & {$[53,215]$} \\
\hline$C Y P 2 A 6^{*} 8$ & SNP in exon 9 produces R485 mutated protein & & [216] \\
\hline$C Y P 2 A 6^{*} 9$ & SNP in TATA box ${ }^{5}$ (decreases promoter activity) & Decreased & {$[56,217-219]$} \\
\hline CYP2A6*10 & Two SNPs in exon 9 (produces 1471T and R486L mutated protein) & Decreased & {$[215,220]$} \\
\hline$C Y P 2 A 6^{*} 11$ & SNP in exon 5 (produces S224P mutated protein) & Decreased & [221] \\
\hline CYP2A6*12 & $\begin{array}{l}\text { Unequal crossover in intron } 2 \text { between CYP2A6 and CYP2A7 (hybrid allele: 5'- } \\
\text { flanking region and exons } 1-2 \text { of CYP2A7; exons } 3-9 \text { and 3'UTR of CYP2A6) } \\
\text { (produces protein with } 10 \text { amino acid substitution with decreased intrinsic activity) }\end{array}$ & Decreased & {$[222,223]$} \\
\hline CYP2A6*17 & $\begin{array}{l}\text { SNPs in exons } 1,3,7 \text {, and } 8 \text { and in introns } 1,6,7 \text {, and } 8 \text { SNP in exon } 7 \text { produces } \\
\text { V365M mutated protein }\end{array}$ & Decreased & {$[43,45,54]$} \\
\hline CYP2A6*18 & SNP in exon 8 produces Y392F mutated protein 6 & Decreased & {$[55,216]$} \\
\hline CYP2A6*19 & SNPs in exon 8 and 9 produce $\mathrm{Y} 392 \mathrm{~F}$ and $1471 \mathrm{~T}$ mutated protein & Decreased & {$[55,216]$} \\
\hline$C Y P 2 A 6^{*} 20$ & $\begin{array}{l}\text { A 2-nucleotide deletion in exon } 4 \text { produces a frame shift at codon 196; results in } \\
\text { premature stop codon at exon } 220 \text { in exon } 5 \text { (truncated protein) }\end{array}$ & No activity & {$[43,224]$} \\
\hline CYP $2 A 6^{*} 21$ & SNP in exon 9 produces K476R mutated protein & Decreased & [43] \\
\hline CYP2A6*22 & SNP in exon 3 produces D158E and L160I mutated protein & Decreased & [225] \\
\hline CYP $2 A 6^{*} 23$ & SNP in exon 4 produces $\mathrm{R} 203 \mathrm{C}$ mutated protein & Decreased & {$[43,45]$} \\
\hline$C Y P 2 A 6 * 24$ & $\begin{array}{l}\text { SNPs in exons } 2 \text { and } 9 \text { produce V110L, N438Y mutated protein; also contains the } \\
\text { same 58bp CYP2A7 } 3^{\prime} \text {-UTR seen in CYP2A6 } 1 B \text { allele }^{7}\end{array}$ & Decreased & [43] \\
\hline CYP $2 A 6 * 25$ & SNP in exon 3 produced F118L mutated protein & Decreased & [43] \\
\hline$C Y P 2 A 6^{*} 26$ & SNPs in exon 3 produce $\mathrm{F} 118 \mathrm{~L}, \mathrm{R} 128 \mathrm{~L}$, and $\mathrm{S} 131 \mathrm{~A}$ mutated protein & Decreased & [43] \\
\hline CYP $2 A 6^{*} 27$ & $\begin{array}{l}\text { SNPs in exon } 3 \text { and } 4 \text { produce F118L mutated protein with frameshift at codon } 203 \\
\text { (R203FS) }\end{array}$ & Decreased & [43] \\
\hline$C Y P 2 A 6 * 28$ & $\begin{array}{l}\text { SNPs in exon } 8 \text { produce a N418D and E419D mutated protein; also contains the } \\
\text { same 58bp CYP2A7 3'-UTR seen in CYP2A6 } 1 B \text { allele }{ }^{8}\end{array}$ & Decreased & [43] \\
\hline CYP2A6*35 & SNP in exon 9 produces $\mathrm{N} 438 \mathrm{Y}$ mutated protein ${ }^{9}$ & Decreased & {$[216,226]$} \\
\hline
\end{tabular}

Table 1: CYP2A6 polymorphisms with proposed effects on nicotine metabolism. (Note: ${ }^{1}$ Two variants of CYP2A $6{ }^{*} 1 \times 2$ have been identified, $\mathrm{CYP} 2 \mathrm{~A} 6^{\star} 1 \times 2 \mathrm{~A}$ and $\mathrm{CYP} 2 \mathrm{~A} 6^{\star} 1 \times 2 \mathrm{~B}$. The two forms are both the product of unequal crossover between CYP2A6 and CYP2A, resulting in a gene 
duplication event; ${ }^{2}$ Seventeen variants of CYP2A $6^{\star} 1 \mathrm{~B}$ have been identified, CYP2A $6{ }^{\star} 1 \mathrm{~B} 1-1 \mathrm{~B} 17$. All variants exhibit a gene conversion in the $3{ }^{\text {' }}$ flanking region, but differ in the position of other concomitant polymorphisms; ${ }^{3} \mathrm{At}$ least eight variants of $\mathrm{CYP} 2 \mathrm{~A} 6^{\star} 4\left(\mathrm{CYP} 2 \mathrm{~A} 6^{\star} 4 \mathrm{~A}-\right.$ $\mathrm{CYP} 2 \mathrm{~A} 6^{\star} 4 \mathrm{H}$ ) have been identified. Variants have all or part of the CYP2A6 $6^{*} 4$ gene deleted, and all are inactive. CYP2A $6^{\star} 4 \mathrm{~A}$ and $\mathrm{CYP} 2 \mathrm{~A} 6^{\star} 4 \mathrm{C}$ are identical and consist only of the $3^{\prime} \mathrm{UTR}$ of CYP2A6. CYP2A6 $6^{\star} 4 \mathrm{~B} ;{ }^{4} \mathrm{CYP} 2 \mathrm{~A} 6^{\star} 5$ may exhibit reduced protein levels due to either reduced mRNA stability or reduced stability of the protein; ${ }^{5}$ Two variants of CYP2A $6^{*} 9$ have been identified, CYP2A6 ${ }^{*} 9 \mathrm{~A}$ and CYP2A6 $6^{\star} 9 \mathrm{~B}$; ${ }^{6} \mathrm{Three}$ variants of $\mathrm{CYP} 2 \mathrm{~A} 6^{*} 18$ have been identified, CYP2A $66^{*} 18 \mathrm{~A}-18 \mathrm{C}$; ${ }^{7}$ Two variants of CYP $2 \mathrm{~A} 6^{\star} 24$ have been identified, $\mathrm{CYP} 2 \mathrm{~A} 6^{*} 24 \mathrm{~A}$ and CYP2A $6{ }^{\star} 24 \mathrm{~B}$; ${ }^{8}$ Two variants of CYP2A $6^{\star} 28$ have been identified, CYP2A6 ${ }^{\star} 28 \mathrm{~A}$ and CYP2A $6{ }^{*} 28 \mathrm{~B}$; ${ }^{9}$ Two variants of CYP2A6*35 have been identified, CYP2A $6 * 35 \mathrm{~A}$ and $\mathrm{CYP} 2 \mathrm{~A} 6^{*} 35 \mathrm{~B}$ )

At least 5 functional isoforms of flavin monooxygenases have been described in humans [67]. FMO isoforms exhibit a tissue-specific pattern of distribution and are found in a wide variety of tissues, which include liver, lung, kidney, and brain, among others. FMO3 catalyzes the $\mathrm{N}$-oxidation of nicotine and is expressed at highest levels in liver. Polymorphisms in the gene encoding FMO3 that result in increased or decreased FMO3 activity have been described. FMO3 deficiency is most important clinically due to its association with trimethylaminuria, or "Fish Odor syndrome," in which patients develop a "rotten fish-like" body odor due to the inability to catalyze the $N$-oxidation of trimethylamines [68]. Individuals with trimethylaminuria have been observed to have impaired $N$-oxidation of nicotine as well [69], suggesting that polymorphisms leading to FMO3 deficiency can affect nicotine metabolism. No studies have been reported examining the effects of FMO3 deficiency on risk of developing nicotine dependence. However, one study comparing nicotine-dependent smokers and nicotine-independent smokers reported an association of nicotine dependence with an SNP in the gene encoding FMO1 (rs10912765), an FMO found in kidney and brain [70].

While normally a minor metabolite of nicotine, urinary nicotine $N$ glucuronide levels can increase in smokers with impaired CYP2A6 activity [66], suggesting an important compensatory role for UGTs in individuals with null alleles for $C Y P 2 A 6$. Nicotine $N$-glucuronide composes $3-5 \%$ of urinary nicotine metabolites in human smokers with normal CYP2A6 activity [26,33]. Nicotine $N$-glucuronide is formed by the action of UDP-glucuronosyltranserases (UGTs), microsomal enzymes found primarily in the liver that catalyze the conjugation of glucuronic acid to a number of drugs during phase II metabolism. In addition to being expressed in liver, UGTs are present in a number of extrahepatic tissues and are abundant in most of the gastrointestinal tract and in the kidney. At least 19 UGT isoforms have been described, and each exhibits a tissue-specific pattern of expression [71]. UGT1A4 is thought to be the primary isoform responsible for hepatic $\mathrm{N}$-glucuronidation of nicotine, although other isoforms, such as UGT1A9 and UGT2B10 may also contribute $[26,72,73]$. Polymorphisms in UGT1A4 and UGT1A9 have been identified that are associated with increased (e.g. UGT1A4 $4^{24 T h}$, UGT1A ${ }^{\star} 22$ ) $N$-glucuronidation activity $[74,75]$ and decreased (e.g. UGT1A ${ }^{\star} 2$, UGT1A9³) $N$-glucuronidation activity [76,77]. However, no studies have evaluated the effects of these polymorphisms on nicotine metabolism in individuals with normal or impaired CYP2A6 function.

Pharmacodynamics of nicotine: Nicotinic acetylcholine receptors (nAChRs) transduce the response to nicotine. Nicotinic AChRs are composed of five membrane-spanning subunits that associate to form a central pore through which cations flow during receptor activation [78]. Nicotinic AChR subunits have similar structural organization to those of other members of the ligand-gated ion channel superfamily (Figure 3). Each subunit is composed of an extracellular N-terminal region, four short transmembrane domains (M1-M4), and a short extracellular C-terminal region. The N-terminal extracellular domain of each subunit contributes to formation of a hydrophobic ligand binding pocket containing multiple extracellular ligand binding sites. The transmembrane region of neuronal nAChRs is organized into an outer and an inner ring. The M2 transmembrane domains of each of the five subunits come together to form the ion-conducting pore of the receptor (inner ring). The M2 domains also contribute to channel "gating" when the receptor is in the unbound state [79]. The other transmembrane domains of each subunit form an "outer ring" encircling the pore formed by the M2 regions. Two short loops link the M1 and M2 domains (intracellular loop) and the M2 and M3 domains (extracellular loop) of each subunit. A longer loop region containing an alpha helix connects the M3 and M4 subunit domains intracellularly. A portion of this long intracellular loop contributes to the charge and size selectivity of the channel. This M3-M4 loop region also contains phosphorylation sites that may contribute to regulation by promoting desensitization in certain nAChRs [80-82].
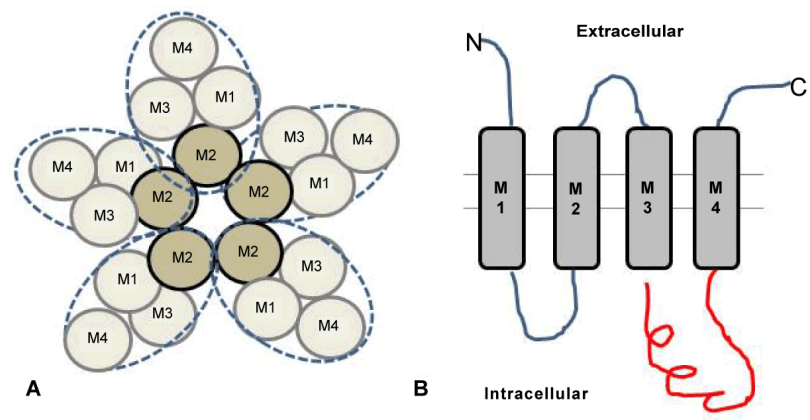

Figure 3: Schematic representations of the basic structure of the nicotinic acetylcholine receptor (nAChR). (A) Each receptor is composed of five subunits, each composed of four transmembrane domains (M1-M4). The M2 domains form the channel pore and contribute to channel gating when the receptor is in the inactive state. The other domains form an outer ring that encircles the M2based pore. (B) The four transmembrane domains (M1-M4) of each subunit are joined by variable length loop regions. Two short loops link the M1 and M2 domains (intracellular loop) and the M2 and M3 domains (extracellular loop). The region joining M3 and M4 is composed of a longer, intracellular loop containing an alpha helix and has a role in channel selectivity and receptor desensitization. The N-terminal extracellular domain of each subunit contributes to the formation of the hydrophobic binding pocket [78-82]. 
Subunit composition of neuronal nAChRs is highly variable and determines the pharmacologic properties of individual receptors. At least twelve isoforms of the nAChR subunits have been described $\left(\alpha_{2}-\right.$ $\alpha_{10}$ and $\beta_{2}-\beta_{4}$ ), and many of these are expressed in the mammalian brain $[7,8,10,78]$. Neuronal nAChRs are either heteromeric (i.e. assembled from a combination of alpha and beta subunits) or homomeric (assembled from alpha subunits only). Ligand binding sites of nAChRs are formed by the extracellular $\mathrm{N}$-terminal regions of adjacent subunits. The "principle component" of each ligand binding site is contributed by alpha subunits. Non-alpha subunits, when present, are thought to contribute a "complementary component" to ligand binding sites that does not appear to be essential to nAChR function but can affect ligand binding affinity, current amplitude, rate of desensitization, and other receptor properties [83-85].

The influence of subunit composition on nAChR response to agonists has been extensively studied $[16,17,78,86,87]$. Heteromeric neuronal nAChRs tend to form from some combination of alpha and beta subunits, generally with the stoichiometry of $\left(\alpha_{x}\right)_{2}\left(\beta_{y}\right)_{3}$, and exhibit a diverse range of binding affinities, ion permeabilities, current amplitudes, and desensitization rates [78]. For example, nAChRs containing $\beta 2$ subunits tend exhibit a higher binding affinity for most ligands than those containing $\beta 4$ subunits [83]. Nicotinic AChRs containing $\beta 2$ subunits also exhibit rapid rates of desensitization that occur at lower concentrations of nicotine than other nAChRs $[17,84]$. Conversely, activated receptors containing $\beta 4$ subunits tend to exhibit higher-amplitude currents than those containing $\beta 2$ subunits [84]. $\alpha 6 \beta 2^{*} \mathrm{nAChRs}$ (asterisk indicates that these subunits are present) on mesolimbic neurons also are important in mediating dopaminedependent effects reinforcing nicotine use [88]. In fact, $\alpha 4 \alpha 6 \beta 2 \beta 3^{\star}$ $n A C h R s$ expressed in the nucleus accumbens and striatum may have the highest sensitivity to nicotine of all native nAChRs [88], suggesting that this receptor population may contribute to early effects of nicotine seen at very at low concentrations.

The $\alpha 7, \alpha 8$, or $\alpha 9$ subunits are capable of forming functional homomeric nAChRs; however, these homopentameric nAChRs tend to exhibit lower binding affinities for agonists and may require higher nicotine concentrations for desensitization than heteromeric nAChRs [78]. In contrast to other $\mathrm{nAChR}$ a subunits, the a5 subunit is considered to be an "orphan" subunit, due to the lack of evidence that it can form a functional receptor without the presence of other functional $\alpha$ - and $\beta$-subunits present in the $\mathrm{nAChR}[78,89,90]$. Orphan subunits can also be called "auxiliary" subunits because they modulate the activity of a nAChR when expressed with functional $\alpha$ - and $\beta$ subunits $[89,90]$. For example, insertion of $\alpha 5$ subunit into a functional $\alpha 4 \beta 2^{*}, \alpha 3 \beta 2^{*}$, or $\alpha 3 \beta 4^{*}$ nAChRs increases calcium permeability of the ion-conducting pore and increases receptor desensitization rate. When expressed with $\alpha 3 \beta 2$ and $\alpha 4 \beta 2$ receptors, $\alpha 5$ alters the potency of certain agonists. Subunit composition also influences coupling of the receptor to downstream $\mathrm{Ca}^{2+}$ pathways [78,91]. The increase in calcium permeability that follows activation of homomeric $\alpha 7 \mathrm{nAChRs}$ is potentiated by downstream activation of $\mathrm{Ca}^{2+}$ induced $\mathrm{Ca}^{2+}$ release in some cell types [92]. Activation of other nAChR types, such as $\alpha 3 \beta 2^{*}, \alpha 3 \beta 4^{*}$ nAChRs, also may be associated with intracellular $\left[\mathrm{Ca}^{2+}\right]$ increases that may involve coupling to voltage-gated calcium channels [93].

Nicotine action in the brain results in a combination of the rewarding effects associated with $\mathrm{nAChR}$ activation in the certain brain regions, and the noxious effects of $\mathrm{nAChR}$ activation in other brain regions $[86,94]$. These effects are dose-dependent and are related to the tendency of smokers to titrate nicotine concentrations by adjusting intake. In the mesolimbic reward pathways, multiple $\mathrm{nAChR}$ subtypes are expressed, each affecting mesolimbic activity differently. Research related to nicotine dependence and smoking cessation has traditionally focused on $\alpha 4 \beta 2^{*}$ receptors, due to the high affinity for ligand binding and early recognition of the high abundance of expression in reward pathways of the human brain [78,95-98]. However, differential expression patterns of nAChRs with distinct subunit composition are likely key determinants of whether specific mesolimbic pathways are up- or downregulated in response to chronic exposure to nicotine. Data suggest that $\alpha 4 \beta 2^{\star} n A C h R s$ are the primary nAChR type located on GABAergic neurons in mesocorticolimbic pathways that downregulate dopamine secretion [99]. These receptors are activated in response to lower concentrations of nicotine and exhibit early rapid desensitization. Homopentameric $\alpha_{7}-$ nAChRs promotes the positive reinforcement effects of nicotine in mesolimbic pathways [100], possibly through enhancing glutamate neurotransmission in the VTA, which upregulates downstream dopamine secretion [101]. In mesolimbic pathways, $\alpha_{7}-n A C h R s$ on glutamatergic neurons require higher nicotine concentrations for activation and for desensitization and therefore desensitize more slowly. The combined effects of nicotine on these two populations of nAChRs produce a net increase in dopamine signaling during the mesolimbic response to nicotine.

Aversive effects are experienced in humans, non-human primates, and rodents in response to high doses of nicotine. These effects likely are mediated via distinct patterns of $\mathrm{nAChR}$ expression and subunit composition [94,102]. The habenulo-interpeduncular tract (medial habenula to interpeduncular nucleus) is a region of the brain involved in suppression of mesolimbic reward pathways and avoidance of noxious stimuli. Nicotinic AChRs are expressed at high levels in the habenulo-interpeduncular tract. Nicotine binding to nAChRs in this tract is associated with an increased current through the channel, which is associated with increased aversion to nicotine. $\alpha 3 \beta 4^{*} \mathrm{nAChRs}$ are abundant in the habenulo-interpeduncular tract. Activation of these receptors require higher nicotine concentrations than $\alpha 4 \beta 2^{*}$ receptors of the mesolimbic pathways. Studies in mice have demonstrated that overexpression of the $\beta 4$ subunit is associated with enhanced activity in the habenulo-interpeduncular tract and increased aversion in response to nicotine [103]. $\alpha 3 \beta 4^{*} \mathrm{nAChRs}$ in this region often assemble with the auxiliary $\alpha 5$ subunit. The $\alpha 5$ and $\beta 4$ subunits appear to have opposing effects, in which $\beta 4$ receptors promote aversion to nicotine by enhancing activation of medial habenular pathways and a5 receptors reduce receptor currents, and thus reduce aversive effects in response to nicotine. This finding is supported by animal studies in which selective knockdown of the $\alpha_{5}$ subunit in the habenulo-interpeduncular tract resulted in significant increases in selfadministration of nicotine [102]. Reintroduction of the CHRNA5 gene by injection of a viral vector into the medial habenular region reversed this effect. Thus, the presence of functional $\alpha 5$ subunits in nAChRs of the habenulo-interpeduncular tract may be important in limiting nicotine intake by mediating negative responses to nicotine.

Polymorphisms affecting nicotine pharmacodynamics: In addition to polymorphisms affecting nicotine's pharmacokinetic parameters, the risk of developing nicotine dependence also can be influenced by polymorphisms affecting the response to nicotine. Nicotine response can be impacted by variation of genes encoding the nicotine receptor subunits, as well as genes encoding key molecules mediating pathways downstream of receptor activation. Examples include components of the dopamine response pathways, such as dopamine receptors and 
dopamine transporters, both of which have known function-altering polymorphisms among humans.

Nicotinic acetylcholine receptor subunit variants: Nicotinic acetylcholine receptor subunits in humans are each encoded by individual genes located on six different chromosomes (chromosomes $1,4,8,11,15$, and 20) [95]. Each gene designation is based on the "CHolinergic Receptor, Nicotinic" (CHRN) nomenclature, with the last letter and number indicating the specific subunit encoded. For example, CHRNA1 indicates the gene encoding the al subunit of nAChR. Some subunits are encoded by genes that are clustered together, a structural characteristic that may allow for common regulatory mechanisms for expression. Two major gene clusters that have been described in detail include the CHRNA5/CHRNA3/ CHRNB4 gene cluster (located at 15q24-25) and the CHRNB3/ CHRNA6 gene cluster (located at $8 \mathrm{p} 11$ ). Other nAChR subunit genes are present at separate loci in the human genome as follows: CHRNA2 (8p21), CHRNA4 (20q13.2-q13.3), CHRNA7 (15q14), CHRNA9 (4p14), CHRNA10(11p15), CHRNB2(1q21) [95].

Genetic variation in the 15q24-25 locus containing the CHRNA3/ CHRNA5/CHRNB4 gene cluster has been widely studied and is implicated in affecting smoking behaviors and a number of smokingrelated outcomes. Of particular interest are the rs1051730 (CHRNA3 variant) and rs16969968 (CHRNA5) risk variants, which have been associated with greater intensity of smoking, number of cigarettes consumed per day, urinary and serum levels of nicotine and nicotine metabolites, and other signs/symptoms of nicotine dependence [104-113]. The mechanism by which these variants associate with nicotine dependence and smoking behaviors is not clear. The rs1051730 variant is a synonymous (missense) SNP in which the change in coding sequence of exon 5 does not result in a change in the amino acid sequence of the protein. The rs16969968 variant is a nonsynonymous SNP, which produces the D398N mutation in the a5 subunit protein. The rs16969968 risk variant (N398) has been associated with a reduced maximal response to agonist when heterologously expressed as a component of a $4 \beta 2 \alpha 5 \mathrm{nAChRs}$ in HEK293 cells [114]. Additionally, when the a5 N398 variant is specifically expressed in the medial habenular region in Tabac mice, mice exhibited increased self-administration of nicotine [103]. Other studies showed that CHRNA5 knockout mice also exhibit an increase in self-administration of nicotine [102]. Taken together, these data suggest that any reduction of a5 subunit function may attenuate negative effects of nicotine and promote excessive nicotine use. Data from human genome-wide meta-analysis studies show associations of the rs16969968 risk variant with smoking behavior and other indicators of nicotine dependence [115-117]. Despite these findings, significant association between rs16969968 risk variants and smoking cessation outcomes is lacking $[118,119]$.

Other variants from the 15q24-25 locus have been associated with increased risk for nicotine dependence and influences on smoking behavior. An intronic variant of CHRNA3 (rs6495308) was associated with a two-fold increased risk for development of nicotine dependence in a study examining the relationship of genotype with daily cigarette consumption rates and patterns [111]. Data suggest that some variants in the 15q24-25 locus may confer protection from development of nicotine dependence. A CHRNA3 SNP in the 3'-UTR (rs578776) has been identified that may have protective effects on risk of nicotine dependence [105,114,120-123]. Interestingly, the CHRNA3 and CHRNA5 genes are positioned tail to tail on opposite strands in the CHRNA3/CHRNA5/CHRNB4 gene cluster, and these genes share part of their 3' UTR [95], therefore, further studies may be needed to determine if this SNP also affects CHRNA5 activity. Rare missense variants in CHRNB4 have also been identified and associated with protection from development of nicotine dependence. Recall that overexpression of $\beta 4 \mathrm{nAChRs}$ in the habenulo-interpeduncular tract reduces nicotine intake by promoting aversive effects of nicotine in rodents [103]. Other studies have suggested that some CHRNB4 variants (rs61737499, rs12914008) may protect against nicotine dependence by reducing craving and withdrawal symptoms [120,124-126] or may increase susceptibility to nicotine dependence (rs56317523) by reducing signaling in habenulo-interpeduncular pathways [126].

Variation in the CHRNA6 and CHRNB3 genes, which may share common regulatory elements, has also been implicated in increased risk for nicotine dependence. Among the CHRNA6/B3 polymorphisms associated with nicotine dependence are the rs13277254 polymorphism, which is located in the region upstream of the $C H R N A 6 / B 3$ gene cluster, and $\mathrm{rs} 4952$, which is a synonymous SNP in the coding region of CHRNB3 [127-130]. However, the exact biological mechanisms by which these associations occur are unclear. Other polymorphisms of this gene cluster that may impact the risk for nicotine dependence include the SNP rs10958726, which occurs in the promoter region of the gene cluster [104], as well as other variants that occur near the CHRNA6/CHRNB3 gene cluster and may correlate with nicotine dependence $[104,130]$.

Some CHRNA4 variants have been implicated in protection from nicotine dependence $[131,132]$, while others have been implicated in increased risk of nicotine dependence [133-136]. However, some findings among these studies were contradictory and thus the role of CHRNA4 polymorphisms in risk for nicotine dependence requires further study for clarification. Variants of the CHRNB2 gene in which changes occur in the regions upstream and downstream of the coding region have also been linked to early nicotine responses and sensitivity to nicotine $[137,138]$, suggesting that polymorphisms in this gene may also contribute to susceptibility to nicotine dependence. Additional studies on the biological significance of CHRNA4 and CHRNB2 gene variants and their impacts on nicotine dependence are warranted, particularly when the importance of $\alpha 4 \beta 2^{\star} n A C h R s$ in reward pathways of the brain are taken into account.

Polymorphisms affecting dopamine pathways involved in nicotine dependence: One of the important effects of nicotine related to development of nicotine dependence is the release of neurotransmitters in the brain, including dopamine. Central dopamine effects are mediated by dopamine binding to dopamine receptors in the brain. There are multiple isoforms of the dopamine receptors that are differentially expressed in the CNS [139]. Two families of dopamine receptors have been described, D1-like receptors and D2-like receptors. Activation of the D1-like receptors, which include the $D_{1}$ and $D_{5}$ dopamine receptors, results in $G$ proteinmediated increases in cAMP production. In contrast, activation of D2like receptors, which include $\mathrm{D}_{2}, \mathrm{D}_{3}$, and $\mathrm{D}_{4}$ dopamine receptors, results in $\mathrm{G}$ protein-mediated decreases in cAMP production. Some $D_{2}$ and $D_{3}$ receptors have been localized to presynaptic locations on brain neurons, and are thus thought to function in autoregulation of dopamine secretion. In addition to differential function of these receptors, the dopamine receptors also exhibit differential expression patterns in brain. The $\mathrm{D}_{1}$ and $\mathrm{D}_{2}$ dopamine receptors both exhibit widespread expression in the brain, whereas the $D_{2}, D_{3}$, and $D_{4}$ 
receptors exhibit more selective expression limited to specific areas of the brain.

The effect of dopamine receptor polymorphisms is of interest in studying the genetic susceptibility to nicotine dependence because any changes that alter the sensitivity of the dopaminergic system could affect risk of developing nicotine dependence. Polymorphisms in the genes encoding the $\mathrm{D}_{2}(D R D 2)$ and $\mathrm{D}_{4}(D R D 4)$ dopamine receptors have been the most studied in relation to risks for developing nicotine dependence $[139,140]$. The DRD2 gene, which encodes the D2 receptor, contains six introns. Variation in intronic sequences leads to long- and short-splice variants of the DRD2 gene product $\left(\mathrm{D}_{2 \mathrm{~L}}\right.$ and $D_{2 S}$, respectively). As a result of alternative splicing, the $D_{2 S}$ variant lacks 29 amino acids that are present in the $\mathrm{D}_{2 \mathrm{~L}}$ variant. Additionally, intronic SNPs have been described that affect relative expression levels of the short- and long-splice variants [141]. A number of restriction fragment length polymorphisms (RFLPs) have been identified in the DRD2 gene using the TaqI enzyme, including the TaqIA (rs1800497), TaqIB (rs1079597), TaqIC, and TaqID (rs1800498) polymorphisms. While associations with smoking behaviors have been reported for these, conflicting data make the functional impact unclear [140,142-145]. Sequence variation in the DRD2 promoter has also been reported (e.g. rs1799732: -141C Del/Ins), and data suggest that these variants are associated with altered expression levels of DRD2 [146], which could have implications on dopaminergic pathways involved in nicotine dependence.

The DRD4 gene, which encodes the $\mathrm{D}_{4}$ dopamine receptor, is the most polymorphic of the dopamine receptor genes. Variants of the DRD4 gene contain a variable number of tandem repeats (VNTR) in exon 3. This VNTR produces changes in the length of the third intracellular loop of the $\mathrm{D}_{4}$ receptor protein due to insertion of 2-10 repeats of a 16-amino acid sequence that occurs in this region $[139,140]$. The functional implications of the exon 3 VNTRs are not well understood, but some studies suggest that VNTR polymorphisms in exon 3 may affect ligand-induced cAMP production, possibly by affecting $\mathrm{D}_{4}$ receptor levels [147-149]. DRD4 polymorphisms associated with tandem repeats in the promoter region approximately $1.2 \mathrm{~kb}$ upstream of the transcription start site have also been described, and a number of studies suggest functional effects on transcriptional activity of the gene [150-152].

Because the dopaminergic system has a major role in mediating nicotine dependence, any polymorphism that changes the efficiency of synaptic clearance of dopamine also would be expected to affect the risk of smokers becoming nicotine dependent. A major mechanism for terminating the effects of dopamine is via the removal of dopamine from the synapse by the dopamine transporter (DAT, encoded by the $S L C 6 A 3$ gene). A number of polymorphisms have been described in DAT genes; however, because coding variants are rare, polymorphisms composed of VNTRs have been the focus of most association studies [139]. Associations of SLC6A3 polymorphisms with nicotine dependence and smoking behaviors have been investigated. For example, studies evaluating the activity of two SLC6A3 VNTRs (40 base pair repeating sequence in the 3'-UTR) have demonstrated that the 9-repeat allele is associated with lower DAT protein levels compared to the 10-repeat allele [153], and individuals expressing the 9-repeat allele exhibit a greater response to smoking cues than smokers with the 10-repeat allele [154,155]. Associations of the 10-repeat allele with early heavy smoking in adolescent smokers have also been reported [156]. The rs27072-A allele of SLC6A3 has been associated with early age of smoking onset $(<18$ years of age $)$ in nicotine dependent smokers [157]. A number of other SLC6A3 polymorphisms have been studied for associations with nicotine dependence and smoking behaviors with varied and sometimes conflicting results $[104,158,159]$.

Other important mechanisms in terminating the dopamine response involve dopamine metabolism. Dopamine is metabolized to homovanillic acid (HVA) by a series of reactions involving the combined actions of monoamine oxidase (MAO-A), aldehyde dehydrogenase, and catechol-O-methyltransferase (COMT). A 30 bp VNTR in the 5'-UTR of the MAO-A gene has been described, and data suggest that the number of repeats in this region influences the transcriptional activity of the gene [139]. A single COMT gene encodes two isoforms of the enzyme, with isoform expression regulated by two distinct promoters in the gene. The longer gene product is membrane-bound, due to the presence of a 50 -amino acid region that forms the transmembrane domain, which is absent in the shorter, soluble COMT isoform. A nonsynonymous SNP (rs4680) causes the Val $\rightarrow$ Met substitution in both the long (codon 158) and short (codon 108) forms of the COMT enzyme that is associated with reduced COMT protein levels and reduced overall COMT activity levels [160]. Another enzyme with a role in dopamine metabolism is dopamine beta hydroxylase, which catalyzes the conversion of dopamine to norepinephrine. At least one polymorphism (rs5320) has been described for the gene encoding this enzyme, and data suggest an influence of this variant on nicotine dependence in elderly Japanese subjects [161].

\section{Pharmacotherapy of nicotine addiction}

Given nicotine's highly addictive nature, successful smoking cessation can be quite difficult. Even with pharmacologic interventions, long-term smoking abstinence rates are generally less than $25 \%[162,163]$. Nicotine replacement therapy (NRT) is currently the first-line therapy for smoking cessation. The rationale for NRT is to reduce the patients craving for cigarettes and to blunt withdrawal symptoms. NRT may be give through transdermal patch, chewing gum, nasal spray, inhaler or lozenges. Numerous randomized clinical trials have demonstrated the effectiveness of NRT in smoking cessation [164]. However, individual results and long-term abstinence rates with NRT can be highly variable. Part of this variation is likely related to a patient's genetic profile with regards to their nicotine addiction phenotype. Smokers who score higher on the Fagerström test for nicotine dependence are less likely to be successful with traditional NRT and may require higher doses or alternative pharmacotherapy. Pharmacogenetic variations in nicotine metabolism or targets may also impact the effectiveness of NRT in specific patients (Table 2).

A number of studies have demonstrated a relationship between CYP2A6 activity and a patient's response to NRT [165-168]. Patients who expressed the $C Y P 2 A \sigma^{*} 1 B$ high activity allele metabolized nicotine faster and were less likely to quit smoking successfully when treated with NRT. Withdrawal symptoms were also more severe in this patient population [39]. In contrast, smokers with reduced activity $C Y P 2 A 6$ variants were twice as likely to quit smoking as those who did not carry the allele [169]. While genetic variants of CYP2B6 do not appear to impact the effectiveness of NRT, they may play a significant role in altering the efficacy of bupropion (see below section).

The enzyme catechol-O-methyltransferase (COMT) is a key enzyme involved in the degradation of dopamine. Nicotine has been shown to stimulate the release of dopamine from ventral tegmental 
neurons and into areas of the brain such as the nucleus accumbens and medial frontal cortex which are involved with the rewarding effects of nicotine. In their comprehensive review, David et al. [170] summarizes genetic association results for 30 candidate genes polymorphisms from two clinical trials in the United Kingdom that utilized transdermal NRT to aid smoking cessation. Of the various polymorphisms studied, the most significant association with NRT effectiveness in smoking cessation was for COMT rs4680. This substitution polymorphism results in a three- to four- fold reduction in COMT activity. Patients with this polymorphism may be more sensitive to the effects of NRT and less susceptible to nicotine dependence. Johnstone et al. [171] in the 2007 Patch study (1686 patients from the United Kingdom) examined the association between COMT genotype and smoking cessation with transdermal NRT. The authors reported a greater efficacy of NRT with regards to abstinence rates in patients with the reduced COMT activity met/met genotype. In contrast, a recent study by Sun et al. [172] reported that sublingual nicotine replacement was more effective in Chinese patients $(\mathrm{N}=249)$ with high COMT activity Val variants than those with the low COMT activity Met allele. This finding differs from those conducted in western populations which reported increased NRT efficacy in patients with the low activity COMT variant. The authors postulate that individuals with the high activity COMT variant may have lower levels of dopamine in their frontal cortex and therefore may be more sensitive to increases in dopamine than those patients with normal or elevated dopamine levels.

Pharmacodynamic variants in $\mathrm{nAChR}$ subunits have been reported to alter a patient's chances for successful smoking cessation and may impact the efficacy of NRT. Several studies have reported an association between CHRNA5-CHRNA3-CHRNA4 variants in the $\mathrm{nAChR}$ and successful smoking cessation. Chen et al. [173] examined data from two smoking cessation trials (5216 total patients of European descent) to determine the impact of $\mathrm{nAChR}$ variant on smoking cessation and relapse. The authors found a significant interaction between genetic variants in CHRNA5-CHRNA3-CHRNA4 and successful smoking cessation. Smokers with high-risk genetic variants showed a three-fold greater likelihood of responding to smoking cessation pharmacotherapy (NRT or bupropion) than those smokers with low-risk genetic variants. A strong association was also reported between CHRNA5-CHRNA3-CHRNA4 haplotypes and the heaviness of smoking. In an earlier study, Munafo et al. [174] reported a weak association between the rs 1051730 polymorphism in the CHRNA3 gene and reduced likelihood of successful smoking cessation at follow-up after NRT transdermal patch. Sarginson et al. [175] reported that polymorphisms in the $15 \mathrm{q} 24$ region, which contained genes for nAChR subunits CHRNA5, CHRNA3, and CHRNA4, could predict the intensity of a smokers craving as well as the severity of their withdrawal symptoms. Data from two studies (571 patients in total) indicated that these polymorphisms were also associated with successful long-term (52 week) smoking abstinence with NRT or bupropion therapy.

There is evidence to suggest that polymorphisms in dopamine receptors may also impact the efficacy of NRT. Dopamine receptor variants have been associated with reduced transcriptional activity and thus reduced dopamine receptor expression [38]. Studies also indicate that dopamine receptor polymorphisms can increase chances that an individual will chose to begin smoking, lower the age at which they start smoking and impede their chances for successful smoking cessation. A 2006 study by Lerman et al. [176] in 368 European smokers showed individuals with the Del C allele of the DRD2 -141C
Ins/Del (rs 1799732) polymorphism had higher quit rates when treated with NRT than those homozygous for the Ins C allele. A 2008 study by David et al. [177] examined the effect of functional polymorphism in the D4 receptor on the efficacy of NRT in 720 smokers of European ancestry. Study results showed that individuals with the variable number of tandem repeats (VNTR) polymorphism in exon III of the dopamine 4 receptor (DRD4) gene had lower abstinence rates at 12 weeks of follow-up.

In addition to NRT a number of other pharmacologic agents have been utilized to aid in smoking cessation. There are currently two nonnicotine drugs approved by the FDA for smoking cessation, varenicline tartrate (Chantix) and bupropion (Zyban). Both are available by prescription. Varenicline is a partial agonist/antagonist at the nicotinic $\alpha 4 \beta 2$ receptor. It was developed from cytisine, a naturally-occurring partial agonist/antagonist at this receptor. Leaves from the golden rain tree (koelreuteria paniculata) have been used for many years by various cultures as both a tobacco substitute and smoking cessation aid. Analysis of the plant shows that it produces alkaloids that are high in cytisine. Stimulation of neuronal $\alpha 4 \beta 2$ receptors by nicotine leads to the release of dopamine in the mesolimbic area, corpus striatum and frontal cortex, areas which are instrumental in the development of nicotine addiction. The partial agonist action of varenicline appears to cause some dopamine release (30-60\%) which blunts the smoker's cravings for nicotine. The drug also competes with nicotine for binding to the $\alpha 4 \beta 2$ receptor and thus reduces the pleasurable sensations that are associated with smoking. Modulation of dopamine release can also reduce craving and withdrawal symptoms during periods of abstinence.

A number of clinical trials have shown that varenicline was significantly better than placebo for both long term smoking abstinence and cessation [178]. Clinical studies have also reported that varenicline was superior to bupropion in reducing the incidence of smoking relapse during a 12 week period $[179,180]$. Despite its shortterm effectiveness, long term (12 months) smoking abstinence rates with varenicline are still only on the order of $20-30 \%$ with great interindividual variability $[39,181]$. A portion of this variability might be attributed to genetic variation in varenicline's target, the nicotinic a4 $\beta 2$ receptor (Table 2). In a 2012 study, King et al. [182] conducted a pharmacogenetic analysis of various candidate genes from 2699 patients enrolled in three clinical trials to determine their effect on the efficacy of varenicline on long-term (9-12 months) smoking abstinence rates. Candidate genes examined included those for nicotinic receptors, metabolizing enzymes, and drug transporters. The authors identified a number of polymorphisms in multiple loci that encoded for various nicotinic receptor subunits which appeared to impact response to varenicline. Two of these, the CHRNA4 and CHRNB2 locion chromosome 15q25, encode the $\alpha 4$ and $\beta 2$ subunits of the nicotinic receptors which are targets for varenicline binding. Other polymorphisms in the CHRNA5/CHRNA3/CHRNB4 gene cluster encoding the $\alpha 5, \alpha 3$, and $\beta 4 \mathrm{nAChR}$ subunits, respectively, were also associated with variations in varenicline response [182]. This is an interesting finding since these loci have likewise shown an association with nicotine dependence $[97,100]$.

The most common adverse effect associated with varenicline use is nausea. The incidence of this adverse effect can be significant and is the most common reason for discontinuance [180]. Swan et al. [183] found a significant association between several acetylcholine receptor subunit variants in the CHRNB2 gene and the severity of nausea. Individuals who possessed minor variants in the CHRNB2 allele 
experienced less varenicline-induced nausea than those without the minor allele. King et al. [182] reported that the chr15q25 locus which includes genes for nicotinic receptor subunits (CHRNB4, CHRNA5 and CHRNA3) was the predominate locus associated with both nicotine dependence and nausea related to varenicline treatment. The authors postulated that the nausea patients experienced while trying to quit may be directly related to nicotine dependence. Smokers with a greater intake of nicotine may be more tolerant to its effects and therefore less likely to experience nausea from varenicline.

In 2011 the FDA identified a small but increased risk of certain cardiovascular events such as angina pectoris, nonfatal myocardial infarction, coronary artery reocclusion and new diagnosis of peripheral vascular disease, in patients using varenicline (http:// www.fda.gov/Drugs/DrugSafety/ucm259161.htm). A systematic review and meta-analysis by Singh et al. [184] confirmed the increased risk for serious cardiovascular events with varenicline when compared to placebo. In addition to cardiovascular effects, the FDA has adding boxed warnings about serious mental health effects that include changes in behavior, depressed mood, hostility, and suicidal thoughts that have occurred in patients taking this drug. Recent evaluation of clinical data suggests that varenicline dramatically increases the risk of suicide and suicide-related behavior when compared with other smoking cessation medications. To date, the basis for these adverse effects has not been fully identified and it is too early to tell at this point if pharmacogenetic variation plays any role in the occurrence of these side effects in patient populations.

Bupropion was initially marketed as an antidepressant however the sustained-release form (Zyban) is FDA-approved for use in smoking cessation. In the brain, bupropion inhibits the reuptake of dopamine and norepinephrine. The mechanism of bupropion's effect in smoking cessation appears to be related to enhanced dopaminergic signaling in the mesolimbic pathways. These pathways and the nucleus accumbens in particular, are important for the perception of nicotine reward. There is also evidence that bupropion might be a weak agonist at certain nAChR. One drawback to the use of bupropion is that it can lower seizure threshold and should not be used in patients with seizure disorders.

The molecular genetics related to bupropion efficacy have been widely investigated (Table 2). A 2012 meta-analysis study by King et al. [182] examined data from three large-scale clinical trials related to smoking cessation therapies. In 826 smokers receiving bupropion, the authors identified an association between $C Y P 2 B 6$ polymorphisms (the primary enzyme responsible for metabolizing bupropion) and the efficacy of bupropion. The CYP2B6 polymorphisms identified by the authors were also associated with increased long-term (9-52 weeks) abstinence rates in smokers treated with bupropion. Lerman et al. [185] found that CYP2B6 slow metabolizers reported greater cigarette cravings and had higher relapse rates. However, the study found that bupropion was able to attenuate the effects of this genotype in female smokers. The effect of this polymorphism was likely not related to changes in bupropion metabolism but rather altered rates of nicotine inactivation. A second study by Lee et al. [64] found that smokers $(\mathrm{N}=147)$ with the CYP2B6* 6 genotype had significantly higher rates of smoking abstinence with bupropion after 10 weeks of treatment and at a 6 month follow-up. In smokers with the CYP2B ${ }^{\star} 1$ genotype $(\mathrm{N}=179)$, bupropion and placebo were equally effective in terms of abstinence. Findings from this study suggest that smokers with the $\mathrm{CYP}^{*} \mathrm{~B}^{\star} 6$ genotype derive significant benefit from bupropion treatment while those with the $\mathrm{CYP}_{2} \mathrm{~B}^{\star} 1$ genotype might benefit from therapies other than bupropion. Patterson et al. [186] examined the relationship between patient rates of nicotine metabolism and the effectiveness of bupropion therapy. In their study of 414 smokers, they found that quit rates for fast nicotine metabolizers were significantly increased by bupropion while those who were slow metabolizers did not benefit from bupropion therapy.

A genome-wide association study by Uhl et al. [187] examined a population of European American smokers $(\mathrm{N}=550)$ who were successful or unsuccessful at smoking abstinence using NRT, bupropion or placebo. The study identified a number of genetic variants in quit-success genes related to cell adhesion, cell enzymes, DNA/RNA and protein processing. The results support the theory that there are many genes that can impact a smoker ability to successfully abstain from smoking. While a number of these genes involved in nicotine dependence and withdrawal may overlap, the genes impacting successful smoking abstinence with bupropion are not necessarily the same as those affecting success with NRT. This conclusion is supported by the fact that the pharmacologic targets for bupropion (dopamine transport) and NRT (nAChR) differ.

A second genome-wide association study by Conti et al. [188] was performed on a patient population of European ancestry $(\mathrm{N}=412)$ who received either bupropion or placebo for smoking cessation. The overall abstinence rate for bupropion was $32 \%$ versus $21.5 \%$ for placebo. By six months abstinence rates had dropped to $25.7 \%$ in the bupropion group and $17.4 \%$ in the placebo group. Using a systembased candidate gene approach, the authors identified a SNP (re2072661) in the $\beta_{2}$ nicotinic acetylcholine receptor subunit (CHRNB2) that significantly impacted abstinence rates at the end of the treatment period and after a six-month follow-up. While the effects of this SNP were independent of treatment, the authors reported a significant difference in relapse rates between those with the SNP and those without at the end of the bupropion treatment period. Relapse rates were higher for patients carrying the minor allele after they stopped taking bupropion than those who were not carriers.

Variations in dopaminergic genes (dopamine transporter, dopamine receptor) have also been reported to alter the efficacy of bupropion in smoking cessation. Leventhal et al. [189] examined the effect of variable number tandem repeat (VNTR) polymorphisms on the efficacy of bupropion for smoking cessation. In a population of 524 smokers of white European descent, the study found that a DRD4 exon III VNTR for the D4 dopamine receptor subtype had a significant effect on bupropion efficacy. Patients with at least on copy on the long or L allele (seven or more repeats) exhibited increased rates of smoking abstinence with bupropion as compared to placebo. Carriers of the L allele also exhibited higher rates of relapse that those with the SS genotype (no copies). Risk of relapse in carriers of the L allele was reduced by bupropion treatment.

Earlier studies by Lerman et al. [176] also identified two variants in dopamine D2 receptors that could alter patient response to bupropion, namely DRD2-141C Ins/Del. Smokers who were homozygous for the Ins $\mathrm{C}$ allele exhibited a better response to bupropion treatment than those with the Del C allele. Conversely, smokers carrying the Del C allele showed statistically higher quit rates with NRT than those homozygous for the Ins $\mathrm{C}$ allele. The results of the study suggest that genotyping of patients with regards to their DRD2 genotype could help identify which patients would be best treated with bupropion or NRT. 


\begin{tabular}{|c|c|c|c|}
\hline $\begin{array}{l}\text { Treatment } \\
\text { Impacted }\end{array}$ & Polymorphism & Effect of Polymorphism & References \\
\hline \multicolumn{4}{|l|}{ NRT: } \\
\hline & CYP $2 A 6^{*} 1 B$ & $\begin{array}{|lr|}\text { Increased } & \text { nicotine } \\
\text { metabolism. } & \text { Reduced } \\
\text { NRT success } & \end{array}$ & [165-168] \\
\hline & COMTrs 4680 & $\begin{array}{l}\text { Reduced COMT activity. } \\
\text { Increased NRT efficacy. }\end{array}$ & {$[171,172]$} \\
\hline & $\begin{array}{l}\text { CHRNA5- } \\
\text { CHRNA3- } \\
\text { CHRNA4 }\end{array}$ & $\begin{array}{l}\text { Alterations in nAChR } \\
\text { activity. } \\
\text { responsiveness to NRT. } \\
\text { May also impact craving } \\
\text { and withdrawal. }\end{array}$ & {$[173-175]$} \\
\hline & $\begin{array}{l}\text { DRD2-141C } \\
\text { Ins/Del }\end{array}$ & $\begin{array}{l}\text { Altered dopamine receptor } \\
\text { expression. Del C allele } \\
\text { associated with increased } \\
\text { NRT efficacy. }\end{array}$ & {$[38,176]$} \\
\hline & DRD4 VNTR & $\begin{array}{l}\text { Reduced likelihood of } \\
\text { abstinence at } 12 \text { weeks. }\end{array}$ & {$[177]$} \\
\hline \multicolumn{4}{|l|}{ Varenicline: } \\
\hline & $\begin{array}{l}\text { CHRNA5- } \\
\text { CHRNA3- } \\
\text { CHRNA4 }\end{array}$ & $\begin{array}{l}\text { Variation in varenicline } \\
\text { response. Nausea with } \\
\text { varenicline treatment. }\end{array}$ & [182] \\
\hline & CHRNB2 & $\begin{array}{l}\text { Nausea with varenicline } \\
\text { treatment. }\end{array}$ & [183] \\
\hline \multicolumn{4}{|l|}{ Bupropion: } \\
\hline & CYP2B6*6 & $\begin{array}{llr}\begin{array}{l}\text { Increased } \\
\text { efficacy } \\
\text { cessation. }\end{array} & \text { in } & \text { smoking } \\
\end{array}$ & [64] \\
\hline & $\begin{array}{lll}\text { DRD4 } & \text { exon III } \\
\text { VNTR } & & \end{array}$ & 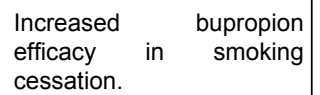 & [189] \\
\hline & $\begin{array}{l}\text { DRD2-141C } \\
\text { Ins/Del }\end{array}$ & 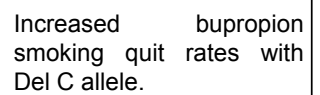 & {$[176]$} \\
\hline & $S L C 6 A 3 / S L C 6 A 4$ & $\begin{array}{l}\text { Altered dopamine } \\
\text { transporter activity. Altered } \\
\text { bupropion efficacy in } \\
\text { smoking cessation. }\end{array}$ & [190-194] \\
\hline \multicolumn{4}{|l|}{ Nortriptyline: } \\
\hline & SLC6A4 & $\begin{array}{|lr|}\text { Altered } & \text { dopamine } \\
\text { transporter } & \text { activity. } \\
\text { Increased } & \text { nortriptyline } \\
\text { efficacy } \text { with } & \text { high activity } \\
\text { variants. } & \end{array}$ & [192-195] \\
\hline \multicolumn{4}{|l|}{$\begin{array}{l}\mathrm{CB}_{1} \\
\text { Antagonists: }\end{array}$} \\
\hline & $D R D 2 \mathrm{~A}_{1}$ & $\begin{array}{lll}\text { Increased } & \text { efficacy } & \text { of } \\
\text { rimonabant } & \text { in } & \text { smoking } \\
\text { cessation } & & \end{array}$ & [198-200] \\
\hline
\end{tabular}

Table 2: Genetic polymorphisms impacting smoking cessation therapies.

A 2007 study by O'Gara et al. [190] (583 smokers) found an association between dopamine transporter gene polymorphisms and short-term smoking abstinence. Patients with the 9-repeat allele variant of the SLC6A3, DAT1 gene were more likely to remain abstinent for 1 week following bupropion or NRT. However, the effect was no longer significant at a 4 -week follow-up. An earlier study by Lerman et al. [191] in 418 smokers likewise reported a positive association between the 9-repeat allele of the dopamine transporter gene and quit rates as well as time to relapse. Genetic variants in serotonin transporter genes may likewise play a role in the efficacy of bupropion for smoking cessation. Quaak et al. [192] examined the effect of serotonin transporter gene variants on the efficacy of bupropion therapy. In a study of 70 mainly Caucasian smokers receiving bupropion, the authors reported that patients carrying the high-activity L-variant (5-HTTLPR) of the serotonin transporter gene (SLC6A4) showed significantly better and longer abstinence rates. This finding is interesting in that it suggests bupropion might have significant effects on serotonin transport that are also related to smoking cessation. The serotonin effect on smoking cessation and abstinence might also be unique to bupropion since earlier studies related to the 5-HTTLPR genotype did not report any association with this variant and NRT effectiveness [193,194]. In 2011, the FDA added boxed warnings about serious mental health events to prescribing information for and bupropion (Zyban, Wellbutrin). An increased risk of serious mental health events including changes in behavior, depressed mood, hostility, and suicidal thoughts have been reported in patients taking these drugs.

Nortriptyline (an antidepressant) and clonidine (used for treatment of hypertension) are not currently approved for smoking cessation therapies but are used as second-line agents. Nortriptyline exerts its pharmacologic effect mainly by inhibiting the reuptake of norepinephrine at nerve terminals. Although studies report that smoking cessation rates may be equivalent to those of bupropion treatment, it remains a second-line agent primarily because of side effects that occur in about three-quarters of patients. Sedation and anticholinergic effects, particularly dry mouth, predominate. A study by Mooney et al. [195] reporting that the association between selfreported nortriptyline side effects and plasma concentrations of drug is weak and inconsistent. Evidence suggests that much of the variability in plasma nortriptyline levels may be due to polymorphisms in CYP2D6 [196]. Genetic variations in the serotonin transporter (5HTT) gene (SLC6A4) located on chromosome 17 might also impact the efficacy of nortriptyline since this transporter is a primary target for the drug. In a study of 214 smokers, Quaak et al. [192] reported that nortriptyline was more effective in smoking cessation following treatment and at 6 and 12 months in patients with 4-5 high activity variants of the serotonin transporter. Other studies have reported that the presence of serotonin transporter variants did not impact smoking cessation rates for NRT $[193,194]$. A case can be made that genetic analysis might be used to identify smokers who would be more likely to respond to nortriptyline based on serotonin transporter variants and who might be least likely to experience side effects based on their CYP2D6 activity. Clonidine, a $\alpha_{2}$-adrenergic receptor agonist, is also used as a second-line agent for smoking cessation and has been employed with some success in the treatment of opioid withdrawal. Significant side effects such as sedation and dry mouth can occur in two-thirds of patients and negatively impact patient compliance. While the efficacy of clonidine in prolonged smoking cessation falls short of other agents [197], it may have a role in treating symptoms of nicotine withdrawal.

Cannabinoid (CB1) receptors are located throughout cerebral cortex, basal ganglia and limbic structures. These receptors appear to 
play a role in regulating food intake as well as in modulating the rewarding effects of nicotine [198]. Studies with knockout mice [199] have demonstrated that the rewarding effects of nicotine were absent when the CB1 receptors were absent. Rimonabant, a selective CB1 endocannabinoid receptor antagonist originally developed for the treatment of obesity, has also been used clinically to aid with smoking cessation. Wilcox et al. [200] reported that the overall effectiveness of rimonabant in smoking cessation was affected by the presence of dopamine receptor gene $(D R D 2)$ polymorphisms. Patients with the DRD2 $\mathrm{A}_{1}{ }^{+}$genotype $\left(\mathrm{A}_{1} / \mathrm{A}_{1}, \mathrm{~A}_{2} / \mathrm{A}_{2}\right)$ are more prone to nicotine dependence. Rimonabant was significantly more effective in smokers with the DRD2 $\mathrm{A}_{1}{ }^{-}$genotype $\left(\mathrm{A}_{2} / \mathrm{A}_{2}\right)$ but showed no benefit in those with the DRD2 $\mathrm{A}_{1}^{+}$genotype. Drugs like rimonabant which antagonize CB1 receptors have the added benefit that they may causes weight loss through appetite suppression and thus help offset the weight gain is often associated with smoking cessation. However, adverse psychiatric events such as anxiety, depression and increased suicide risk led to the drug being removed from the market and are limiting factors in the potential further development of this class of agents. Lazary et al. [201] suggested that genomic screening might allow for the safe use of CB1 antagonists in selected populations with a reduced risk of adverse effects. The negative psychiatric effects of rimonabant were reported to be dose-dependent. Since rimonabant is metabolized by CYP450 enzymes it is possible that the risk for potential side effects would be increased in patients who were "slow metabolizers" of the drug. A rodent study by Beyer et al. [202] reported that chronic treatment with rimonabant caused significant reduction in cortical serotonin levels which might explain the depressive effects of the drug. Known polymorphisms in the serotonin transporter (SERT) gene (SLC6A4) or the CB1 receptor gene (CNRI) could potentially enhance the negative effects of CB1 antagonists in patients with these variants.

Genetic testing and pharmacotherapy: A considerable body of evidence suggests that a patient's likelihood of long-term smoking cessation is influenced by their genetic make-up. The efficacy of various pharmacologic interventions for smoking cessation is likewise altered by pharmacokinetic and pharmacodynamic genetic variants within that patient. Genetic screening of patients prior to selecting a particular pharmacotherapeutic intervention could help physicians chose agents (or doses of a particular agent) that would have a greater likelihood for success in that particular patient. For example, patients with high activity variants of CYP2B6 might require higher doses of bupropion or be better candidates for NRT. Conversely, CYP2A6 rapid metabolizers have been shown to respond better to treatment with bupropion since this enzyme is involved in the metabolism of nicotine. Genetic testing might also be used to select appropriate drug doses. Rose et al. [203] divided 457 smokers into two distinct subsets based on their "quit-success" genotype scores. These scores were based on an assessment of alleles at 12,058 SNP's identified in previous studies as significantly impacting a patient's chances for successful smoking cessation. Patients were treated with NRT for 10 weeks at a low $(21 \mathrm{mg})$ or high $(42 \mathrm{mg})$ dose. Data from the study revealed that high dose NRT was most effective in highly dependent smokers with a low quit success genotype. This study exemplifies how genotyping could be used to choose the best dose of NRT for a specific patient population. Interestingly, the high dose of NRT actually reduced smoking cessation success rates in patients who were less smoking dependent and had low quit success genotype. Variations in the drug receptor targets such as the nicotinic acetylcholine receptor and dopamine (D2, D4) receptors can also impact the efficacy of specific pharmacotherapies. A study by Lerman et al. [176] examined the effect of genetic variation in dopamine D2 receptors on efficacy of NRT and bupropion. Their findings suggest that bupropion might be more efficacious in smokers homozygous for the DRD2-141 Ins $C$ allele (associated with increased transcriptional efficiency) while NRT might be the preferred treatment in patients carrying the Del $C$ allele. In effect, patients with reduced dopamine receptor numbers or activity would likely be better candidates for NRT while those with enhanced receptor activity or number might be better suited for bupropion therapy. In addition to optimizing pharmacotherapy, genetic testing may also be used to reduce the occurrence of adverse effects since the likelihood of adverse effect increases in the patients with specific genetic variants in metabolizing enzymes, drug transporters and target receptors.

Several studies have also examined the potential cost-effectiveness of using pharmacogenetic testing to individualize smoking cessation therapies. Heitjan et al. [204] used a Monte Carlo simulation with 40,000 hypothetical smokers and data from several clinical trials of tobacco dependence to evaluate the cost-effectiveness of various smoking-cessation therapies both alone and in conjunction with the use of a genetic test to choose the therapy. The DRD2-141c Ins/Del polymorphism was chosen as the modifier for treatment therapy. Successful smoking cessation therapy in general has been found to be cost effective given its ability to offset the long-term costs associated with the development of smoking-related health conditions [205]. According to Heitjan et al. [204] under appropriate conditions, a pharmacogenetic-based treatment regimen can both reduce costs and increase patient survival time when compared to a generalized treatment regimen. A 2012 pilot study by McClure et al. [205] demonstrated that it was possible to effectively deliver a personalized program for smoking cessation that included genetic testing, counseling and pharmacotherapy of patients without face-to-face contact. Subjects enrolled in the study returned saliva samples for ANKK1 rs 1800497 genotyping and conitine analyses to confirm smoking cessation during the trial. Behavioral counseling was conducted by phone and personalized pharmacotherapy (NRT or bupropion based on genotype) delivered to patients by mail.

Although there is a significant body of literature regarding the pharmacogenetics of nicotine addiction and smoking cessation therapies, research in this area poses a number of inherent challenges and findings should be interpreted with caution. Many pharmacogenetic studies of smoking and smoking cessation examine only one particular target or gene. Others may only include patients of a single sex or ethnic background. Nicotine addiction and withdrawal are highly complex phenomenon not governed by a single gene. Numerous genes are likely involved in the development of addiction, efficacy of pharmacotherapy and manifestations of withdrawal. Results from the genome-wide association study by Uhl et al. [187] highlight that fact. Genetic variants associated with successful smoking cessation with NRT or bupropion were not only related to substance dependence and memory but also to cell adhesion, enzyme activity and transcriptional, structural and protein-handling. Complex interactions between gene expression and environmental influences must also be considered along with the potential impact of other nongenetic factors such as lifestyle, age, and diet. The act of smoking likewise has a significant behavioral and social component that is difficult to quantify and define. 


\section{Summary}

Although significant progress has been made in recent years with regards to our understanding of nicotine addiction, many important questions remain unanswered. One is the role that an individual's genetic make-up plays in both altering their risk for nicotine addiction as well as modulating the severity of that addiction once it occurs. A second is the role that individual genetic variation plays in altering the potential efficacy nicotine replacement and other pharmacotherapies.

The mesolimbic region of the brain plays an important role in the addicting and rewarding effects of nicotine. Genetic variation in the enzymes that metabolize nicotine can significantly alter plasma levels of nicotine and its metabolites and thus alter the concentrations that reach the brain. Polymorphisms in nicotinic acetylcholine receptors and components of dopaminergic pathways within the mesolimbic system can likewise modulate the addictive and rewarding effects of nicotine. Studies also suggest that the severity of an individual's withdrawal from nicotine may be affected by genetic variation in these same pharmacokinetic and pharmacodynamic pathways.

While treatment options for nicotine addiction have expanded significantly in recent years, their overall effectiveness in long-term smoking abstinence is still disappointing. A better understanding of genetic variations in brain pathways associated with nicotine addiction and reward will likely lead to greater individualization of smoking cessation therapies and perhaps the development of new therapies that are more efficacious and cost-effective.

\section{References}

1. Centers for Disease Control and Prevention (CDC) (2003) Cigarette smoking-attributable morbidity---United States, 2000. MMWR Morb Mortal Wkly Rep 52: 842-844.

2. Adhikari B, Kahende J, Malarcher A, Pechacke T, Tong V (2008) Smoking-attributable mortality, years of potential life lost, and productivity losses, United States, 2000-2004. MMWR 57: 1226-1228.

3. Centers for Disease Control and Prevention (CDC) (2009) Cigarette smoking among adults and trends in smoking cessation - United States, 2008. MMWR Morb Mortal Wkly Rep 58: 1227-1232.

4. Shiffman S, Scharf DM, Shadel WG, Gwaltney CJ, Dang Q, et al. (2006) Analyzing milestones in smoking cessation: illustration in a nicotine patch trial in adult smokers. J Consult Clin Psychol 74: 276-285.

5. Balfour DJ (2002) Neuroplasticity within the mesoaccumbens dopamine system and its role in tobacco dependence. Curr Drug Targets CNS Neurol Disord 1: 413-421.

6. Benowitz NL (2009) Pharmacology of nicotine: addiction, smokinginduced disease, and therapeutics. Annu Rev Pharmacol Toxicol 49: 57-71.

7. Dani JA, Jensen D, Brossard JI, De Basi M (2011) Neurophysiology of nicotine addiction. J Addict Res Ther Suppl S1.

8. D'Souza MS, Markou A (2011) Neuronal mechanisms underlying development of nicotine dependence: implications for novel smokingcessation treatments. Addict Sci Clin Pract 6: 4-16.

9. Dani JA, De Biasi M (2013) Mesolimbic dopamine and habenulointerpeduncular pathways in nicotine withdrawal. Cold Spring Harb Perspect Med 3.

10. Benowitz NL (2010) Nicotine addiction. N Engl J Med 362: 2295-2303.

11. Mansvelder HD, McGehee DS (2002) Cellular and synaptic mechanisms of nicotine addiction. J Neurobiol 53: 606-617.

12. Nestler EJ (2005) Is there a common molecular pathway for addiction? Nat Neurosci 8: 1445-1449.
13. Laviolette SR, van der Kooy D (2004) The neurobiology of nicotine addiction: bridging the gap from molecules to behaviour. Nat Rev Neurosci 5: 55-65.

14. Carboni E, Bortone L, Giua C, Di Chiara G (2000) Dissociation of physical abstinence signs from changes in extracellular dopamine in the nucleus accumbens and in the prefrontal cortex of nicotine dependent rats. Drug Alcohol Depend 58: 93-102.

15. Pidoplichko VI, DeBiasi M, Williams JT, Dani JA (1997) Nicotine activates and desensitizes midbrain dopamine neurons. Nature 390: 401-404.

16. Mansvelder HD, Keath JR, McGehee DS (2002) Synaptic mechanisms underlie nicotine-induced excitability of brain reward areas. Neuron 33: 905-919.

17. Wooltorton JR, Pidoplichko VI, Broide RS, Dani JA (2003) Differential desensitization and distribution of nicotinic acetylcholine receptor subtypes in midbrain dopamine areas. J Neurosci 23: 3176-3185.

18. Fowler JS, Logan J, Wang GJ, Volkow ND (2003) Monoamine oxidase and cigarette smoking. Neurotoxicology 24: 75-82.

19. Lewis A, Miller JH, Lea RA (2007) Monoamine oxidase and tobacco dependence. Neurotoxicology 28: 182-195.

20. Oreland L, Fowler CJ, Schalling D (1981) Low platelet monoamine oxidase activity in cigarette smokers. Life Sci 29: 2511-2518.

21. Fowler JS, Volkow ND, Logan J, Pappas N, King P, et al. (1998) An acute dose of nicotine does not inhibit MAO B in baboon brain in vivo. Life Sci 63: PL19-23.

22. Fowler JS, Volkow ND, Wang GJ, Pappas N, Logan J, et al. (1996) Inhibition of monoamine oxidase B in the brains of smokers. Nature 379: 733-736.

23. Fowler JS, Wang GJ, Volkow ND, Franceschi D, Logan J, et al. (2000) Maintenance of brain monoamine oxidase B inhibition in smokers after overnight cigarette abstinence. Am J Psychiatry 157: 1864-1866.

24. Exley R, Cragg SJ (2008) Presynaptic nicotinic receptors: a dynamic and diverse cholinergic filter of striatal dopamine neurotransmission. $\mathrm{Br} \mathrm{J}$ Pharmacol 153 Suppl 1: S283-297.

25. Brody AL, Mandelkern MA, London ED, Olmstead RE, Farahi J, et al. (2006) Cigarette smoking saturates brain alpha 4 beta 2 nicotinic acetylcholine receptors. Arch Gen Psychiatry 63: 907-915.

26. Hukkanen J, Jacob P 3rd, Benowitz NL (2005) Metabolism and disposition kinetics of nicotine. Pharmacol Rev 57: 79-115.

27. Marks MJ, Burch JB, Collins AC (1983) Effects of chronic nicotine infusion on tolerance development and nicotinic receptors. J Pharmacol Exp Ther 226: 817-825.

28. Schwartz RD, Kellar KJ (1983) Nicotinic cholinergic receptor binding sites in the brain: regulation in vivo. Science 220: 214-216.

29. Buisson B, Bertrand D (2001) Chronic exposure to nicotine upregulates the human (alpha)4((beta)2 nicotinic acetylcholine receptor function. J Neurosci 21: 1819-1829.

30. De Biasi M, Dani JA (2011) Reward, addiction, withdrawal to nicotine. Annu Rev Neurosci 34: 105-130.

31. Bradberry CW, Lory JD, Roth RH (1991) The anxiogenic beta-carboline FG 7142 selectively increases dopamine release in rat prefrontal cortex as measured by microdialysis. J Neurochem 56: 748-752.

32. Lavielle S, Tassin JP, Thierry AM, Blanc G, Herve D, et al. (1979) Blockade by benzodiazepines of the selective high increase in dopamine turnover induced by stress in mesocortical dopaminergic neurons of the rat. Brain Res 168: 585-594.

33. Benowitz NL, Porchet H, Jacob P III (1990) Pharmacokinetics, metabolism, and pharmacodynamics of nicotine. In Wonnacott S, Russell MAH, Stolerman IP (eds) Nicotine Psychopharmacology: Molecular Cellular, \& Behavioural Aspects. Oxford University Press, Oxford, England, pp: 112-157.

34. Nakajima M, Yamamoto T, Nunoya K, Yokoi T, Nagashima K, et al. (1996) Role of human cytochrome P4502A6 in C-oxidation of nicotine. Drug Metab Dispos 24: 1212-1217. 
35. Messina ES, Tyndale RF, Sellers EM (1997) A major role for CYP2A6 in nicotine C-oxidation by human liver microsomes. J Pharmacol Exp Ther 282: 1608-1614

36. Yamazaki H, Inoue $\mathrm{K}$, Hashimoto $\mathrm{M}$, Shimada $\mathrm{T}$ (1999) Roles of CYP2A6 and CYP2B6 in nicotine C-oxidation by human liver microsomes. Arch Toxicol 73: 65-70.

37. Malaiyandi V, Sellers EM, Tyndale RF (2005) Implications of CYP2A6 genetic variation for smoking behaviors and nicotine dependence. Clin Pharmacol Ther 77: 145-158.

38. Quaak M, van Schayck CP, Knaapen AM, van Schooten FJ (2009) Genetic variation as a predictor of smoking cessation success. A promising preventive and intervention tool for chronic respiratory diseases? Eur Respir J 33: 468-480.

39. Kubota T, Nakajima-Taniguchi C, Fukuda T, Funamoto M, Maeda M, et al. (2006) CYP2A6 polymorphisms are associated with nicotine dependence and influence withdrawal symptoms in smoking cessation. Pharmacogenomics J 6: 115-119.

40. Rao Y, Hoffmann E, Zia M, Bodin L, Zeman M, et al. (2000) Duplications and defects in the CYP2A6 gene: identification, genotyping, and in vivo effects on smoking. Mol Pharmacol 58: 747-755.

41. Kumasaka N, Aoki M, Okada Y, Takahashi A, Ozaki K, et al. (2012) Haplotypes with copy number and single nucleotide polymorphisms in CYP2A6 locus are associated with smoking quantity in a Japanese population. PLoS One 7: e44507.

42. Pianezza ML, Sellers EM, Tyndale RF (1998) Nicotine metabolism defect reduces smoking. Nature 393: 750 .

43. Mwenifumbo JC, Al Koudsi N, Ho MK, Zhou Q, Hoffmann EB, et al. (2008) Novel and established CYP2A6 alleles impair in vivo nicotine metabolism in a population of Black African descent. Hum Mutat 29: 679-688.

44. Schoedel KA, Hoffmann EB, Rao Y, Sellers EM, Tyndale RF (2004) Ethnic variation in CYP2A6 and association of genetically slow nicotine metabolism and smoking in adult Caucasians. Pharmacogenetics 14: 615-626.

45. Ho MK, Mwenifumbo JC, Zhao B, Gillam EM, Tyndale RF (2008) A novel CYP2A6 allele, CYP2A $6^{\star} 23$, impairs enzyme function in vitro and in vivo and decreases smoking in a population of Black-African descent. Pharmacogenet Genomics 18: 67-75.

46. Liu T, David SP, Tyndale RF, Wang H, Zhou Q, et al. (2011) Associations of CYP2A6 genotype with smoking behaviors in southern China. Addiction 106: 985-994

47. Zhu AZ, Binnington MJ, Renner CC, Lanier AP, Hatsukami DK, et al. (2013) Alaska native smokers and smokeless tobacco users with slower CYP2A6 activity have lower tobacco consumption, lower tobacco specific nitrosamine exposure and lower tobacco specific nitrosamine bioactivation. Carcinogenesis 108: 1818-1828.

48. Raunio H, Rahnasto-Rilla M (2012) CYP2A6: genetics, structure, regulation, and function. Drug Metabol Drug Interact 27: 73-88.

49. Mwenifumbo JC, Tyndale RF (2007) Genetic variability in CYP2A6 and the pharmacokinetics of nicotine. Pharmacogenomics 8: 1385-1402.

50. Yamano S, Tatsuno J, Gonzalez FJ (1990) The CYP2A3 gene product catalyzes coumarin 7-hydroxylation in human liver microsomes. Biochemistry 29: 1322-1329.

51. Hadidi H, Zahlsen K, Idle JR, Cholerton S (1997) A single amino acid substitution (Leu160His) in cytochrome P450 CYP2A6 causes switching from 7-hydroxylation to 3-hydroxylation of coumarin. Food Chem Toxicol 35: 903-907.

52. Kitagawa K, Kunugita N, Kitagawa M, Kawamoto T (2001) CYP2A6*6, a novel polymorphism in cytochrome p450 2A6, has a single amino acid substitution (R128Q) that inactivates enzymatic activity. J Biol Chem 276: $17830-17835$

53. Ariyoshi N, Sawamura Y, Kamataki T (2001) A novel single nucleotide polymorphism altering stability and activity of CYP2a6. Biochem Biophys Res Commun 281: 810-814.
54. Fukami T, Nakajima M, Yoshida R, Tsuchiya Y, Fujiki Y, et al. (2004) A novel polymorphism of human CYP2A6 gene CYP2A6*17 has an amino acid substitution (V365M) that decreases enzymatic activity in vitro and in vivo. Clin Pharmacol Ther 76: 519-527.

55. Fukami T, Nakajima M, Higashi E, Yamanaka H, Sakai H, et al. (2005) Characterization of novel CYP2A6 polymorphic alleles (CYP2A6*18 and CYP2A6*19) that affect enzymatic activity. Drug Metab Dispos 33: 1202-1210.

56. Pitarque M, von Richter O, Oke B, Berkkan H, Oscarson M, et al. (2001) Identification of a single nucleotide polymorphism in the TATA box of the CYP2A6 gene: impairment of its promoter activity. Biochem Biophys Res Commun 284: 455-460.

57. von Richter O, Pitarque M, Rodríguez-Antona C, Testa A, Mantovani R, et al. (2004) Polymorphic NF-Y dependent regulation of human nicotine C-oxidase (CYP2A6). Pharmacogenetics 14: 369-379.

58. Fukami T, Nakajima M, Yamanaka H, Fukushima Y, McLeod HL, et al. (2007) A novel duplication type of CYP2A6 gene in African-American population. Drug Metab Dispos 35: 515-520.

59. Wang J, Pitarque M, Ingelman-Sundberg M (2006) 3'-UTR polymorphism in the human CYP2A6 gene affects mRNA stability and enzyme expression. Biochem Biophys Res Commun 340: 491-497.

60. Oscarson M, McLellan RA, Gullstén H, Agúndez JA, Benítez J, et al. (1999) Identification and characterisation of novel polymorphisms in the CYP2A locus: implications for nicotine metabolism. FEBS Lett 460: 321-327.

61. Mwenifumbo JC, Lessov-Schlaggar CN, Zhou Q, Krasnow RE, Swan GE, et al. (2008) Identification of novel CYP2A $66^{\star} 1 \mathrm{~B}$ variants: the CYP2A $6^{*} 1 \mathrm{~B}$ allele is associated with faster in vivo nicotine metabolism. Clin Pharmacol Ther 83: 115-121.

62. Al Koudsi N, Tyndale RF (2010) Hepatic CYP2B6 is altered by genetic, physiologic, and environmental factors but plays little role in nicotine metabolism. Xenobiotica 40: 381-392.

63. Binnington MJ, Zhu AZ, Renner CC, Lanier AP, Hatsukami DK, et al. (2012) CYP2A6 and CYP2B6 genetic variation and its association with nicotine metabolism in South Western Alaska Native people. Pharmacogenet Genomics 22: 429-440.

64. Lee AM, Jepson C, Hoffmann E, Epstein L, Hawk LW, et al. (2007) CYP2B6 genotype alters abstinence rates in a bupropion smoking cessation trial. Biol Psychiatry 62: 635-641.

65. Zhu AZ, Cox LS, Nollen N, Faseru B, Okuyemi KS, et al. (2012) CYP2B6 and bupropion's smoking-cessation pharmacology: the role of hydroxybupropion. Clin Pharmacol Ther 92: 771-777.

66. Yamanaka H, Nakajima M, Nishimura K, Yoshida R, Fukami T, et al. (2004) Metabolic profile of nicotine in subjects whose CYP2A6 gene is deleted. Eur J Pharm Sci 22: 419-425.

67. Hisamuddin IM, Yang VW (2007) Genetic polymorphisms of human flavin-containing monooxygenase 3: implications for drug metabolism and clinical perspectives. Pharmacogenomics 8: 635-643.

68. Dolphin CT, Janmohamed A, Smith RL, Shephard EA, Phillips IR (1997) Missense mutation in flavin-containing mono-oxygenase 3 gene, FMO3, underlies fish-odour syndrome. Nat Genet 17: 491-494.

69. Al-Waiz M, Ayesh R, Crothers J, Idle JR, Mitchell SC, et al. (1988) Deficient nicotine $\mathrm{N}$-oxidation in two sisters with trimethylaminuria. Br J Clin Pharmacol 25: 664-665.

70. Hinrichs AL, Murphy SE, Wang JC, Saccone S, Saccone N, et al. (2011) Common polymorphisms in FMO1 are associated with nicotine dependence. Pharmacogenet Genomics 21: 397-402.

71. Bock KW (2012) Human UDP-glucuronosyltransferases: feedback loops between substrates and ligands of their transcription factors. Biochem Pharmacol 84: 1000-1006.

72. Nakajima M, Yokoi $T$ (2005) Interindividual variability in nicotine metabolism: C-oxidation and glucuronidation. Drug Metab Pharmacokinet 20: 227-235. 
73. Kaivosaari S, Toivonen P, Hesse LM, Koskinen M, Court MH, et al. (2007) Nicotine glucuronidation and the human UDPglucuronosyltransferase UGT2B10. Mol Pharmacol 72: 761-768.

74. Weiner D, Fang J-L, Dossett N, Lazarus P (2004) Correlation between UDP-glucuronosyltransferase genotypes and 4-(methylnitrosamino)-1(3-pyridyl)-1 butanone glucuronidation phenotype in human liver microsomes. Cancer Res 64: 1190-1196.

75. Yamanaka H, Nakajima M, Katoh M, Hara Y, Tachibana O, et al. (2004) A novel polymorphism in the promoter region of human UGT1A9 gene (UGT1A9 22 ) and its effects on the transcriptional activity. Pharmacogenetics 14: 329-332.

76. Villeneuve L, Girard H, Fortier LC, Gagné JF, Guillemette C (2003) Novel functional polymorphisms in the UGT1A7 and UGT1A9 glucuronidating enzymes in Caucasian and African-American subjects and their impact on the metabolism of 7-ethyl-10-hydroxycamptothecin and flavopiridol anticancer drugs. J Pharmacol Exp Ther 307: 117-128.

77. Wang H, Yuan L, Zeng S (2011) Characterizing the effect of UDPglucuronosyltransferase (UGT) 2B7 and UGT1A9 genetic polymorphisms on enantioselective glucuronidation of flurbiprofen. Biochem Pharmacol 82: 1757-1763.

78. Kalamida D, Poulas K, Avramopoulou V, Fostieri E, Lagoumintzis G, et al. (2007) Muscle and neuronal nicotinic acetylcholine receptors. Structure, function and pathogenicity. FEBS J 274: 3799-3845.

79. Unwin N (2005) Refined structure of the nicotinic acetylcholine receptor at 4A resolution. J Mol Biol 346: 967-989.

80. Downing JE, Role LW (1987) Activators of protein kinase C enhance acetylcholine receptor desensitization in sympathetic ganglion neurons. Proc Natl Acad Sci U S A 84: 7739-7743.

81. Huganir RL, Greengard P (1990) Regulation of neurotransmitter receptor desensitization by protein phosphorylation. Neuron 5: 555-567.

82. Khiroug L, Sokolova E, Giniatullin R, Afzalov R, Nistri A (1998) Recovery from desensitization of neuronal nicotinic acetylcholine receptors of rat chromaffin cells is modulated by intracellular calcium through distinct second messengers. J Neurosci 18: 2458-2466.

83. Xiao Y, Kellar KJ (2004) The comparative pharmacology and upregulation of rat neuronal nicotinic receptor subtype binding sites stably expressed in transfected mammalian cells. J Pharmacol Exp Ther 310: 98-107.

84. Wu J, Liu Q, Yu K, Hu J, Kuo YP, et al. (2006) Roles of nicotinic acetylcholine receptor beta subunits in function of human alpha4containing nicotinic receptors. J Physiol 576: 103-118.

85. Kuryatov A, Onksen J, Lindstrom J (2008) Roles of accessory subunits in alpha4beta2 $\left(^{*}\right)$ nicotinic receptors. Mol Pharmacol 74: 132-143.

86. Tuesta LM, Fowler CD, Kenny PJ (2011) Recent advances in understanding nicotinic receptor signaling mechanisms that regulate drug self-administration behavior. Biochem Pharmacol 82: 984-995.

87. Improgo MR, Scofield MD, Tapper AR, Gardner PD (2010) The nicotinic acetylcholine receptor CHRNA5/A3/B4 gene cluster: dual role in nicotine addiction and lung cancer. Prog Neurobiol 92: 212-226.

88. Grady SR, Salminen O, Laverty DC, Whiteaker P, McIntosh JM, et al. (2007) The subtypes of nicotinic acetylcholine receptors on dopaminergic terminals of mouse striatum. Biochem Pharmacol 74: 1235-1246.

89. Ramirez-Latorre J, Yu CR, Qu X, Perin F, Karlin A, et al. (1996) Functional contributions of alpha5 subunit to neuronal acetylcholine receptor channels. Nature 380: 347-351.

90. Wang F, Gerzanich V, Wells GB, Anand R, Peng X, et al. (1996) Assembly of human neuronal nicotinic receptor alpha5 subunits with alpha3, beta2, and beta4 subunits. J Biol Chem 271: 17656-17665

91. Tsuneki H, Klink R, Léna C, Korn H, Changeux JP (2000) Calcium mobilization elicited by two types of nicotinic acetylcholine receptors in mouse substantia nigra pars compacta. Eur J Neurosci 12: 2475-2485.

92. Sharma G, Vijayaraghavan S (2001) Nicotinic cholinergic signaling in hippocampal astrocytes involves calcium-induced calcium release from intracellular stores. Proc Natl Acad Sci U S A 98: 4148-4153.
93. Dajas-Bailador FA, Mogg AJ, Wonnacott S (2002) Intracellular Ca2+ signals evoked by stimulation of nicotinic acetylcholine receptors in $\mathrm{SH}-$ SY5Y cells: contribution of voltage-operated $\mathrm{Ca} 2+$ channels and $\mathrm{Ca} 2+$ stores. J Neurochem 81: 606-614.

94. Fowler CD, Kenny PJ (2014) Nicotine aversion: Neurobiological mechanisms and relevance to tobacco dependence vulnerability. Neuropharmacology 76 Pt B: 533-544.

95. Greenbaum L, Lerer B (2009) Differential contribution of genetic variation in multiple brain nicotinic cholinergic receptors to nicotine dependence: recent progress and emerging open questions. Mol Psychiatry 14: 912-945.

96. Picciotto MR, Zoli M, Rimondini R, Léna C, Marubio LM, et al. (1998) Acetylcholine receptors containing the beta2 subunit are involved in the reinforcing properties of nicotine. Nature 391: 173-177.

97. Tapper AR, McKinney SL, Nashmi R, Schwarz J, Deshpande P, et al. (2004) Nicotine activation of alpha $4^{*}$ receptors: sufficient for reward, tolerance, and sensitization. Science 306: 1029-1032.

98. Pons S, Fattore L, Cossu G, Tolu S, Porcu E, et al. (2008) Crucial role of alpha4 and alpha6 nicotinic acetylcholine receptor subunits from ventral tegmental area in systemic nicotine self-administration. J Neurosci 28: 12318-12327.

99. Klink R, de Kerchove d'Exaerde A, Zoli M, Changeux JP (2001) Molecular and physiological diversity of nicotinic acetylcholine receptors in the midbrain dopaminergic nuclei. J Neurosci 21: 1452-1463.

100. Besson M, David V, Baudonnat M, Cazala P, Guilloux JP, et al. (2011) Alpha7-nicotinic receptors modulate nicotine-induced reinforcement and extracellular dopamine outflow in the mesolimbic system in mice. Psychopharmacology (Berl) 220: 1-14.

101. Jones IW, Wonnacott S (2004) Precise localization of alpha7 nicotinic acetylcholine receptors on glutamatergic axon terminals in the rat ventral tegmental area. J Neurosci 24: 11244-11252.

102. Fowler CD, Lu Q, Johnson PM, Marks MJ, Kenny PJ (2011) Habenular Î \pm 5 nicotinic receptor subunit signalling controls nicotine intake. Nature 471: 597-601.

103. Frahm S, Slimak MA, Ferrarese L, Santos-Torres J, Antolin-Fontes B, et al. (2011) Aversion to nicotine is regulated by the balanced activity of $\hat{I}^{2} 4$ and $\hat{I} \pm 5$ nicotinic receptor subunits in the medial habenula. Neuron 70 : 522-535.

104. Saccone SF, Hinrichs AL, Saccone NL, Chase GA, Konvicka K, et al. (2007) Cholinergic nicotinic receptor genes implicated in a nicotine dependence association study targeting 348 candidate genes with 3713 SNPs. Hum Mol Genet 16: 36-49.

105. Saccone NL, Saccone SF, Hinrichs AL, Stitzel JA, Duan W, et al. (2009) Multiple distinct risk loci for nicotine dependence identified by dense coverage of the complete family of nicotinic receptor subunit (CHRN) genes. Am J Med Gen 150B: 453-466.

106. Le Marchand L, Derby KS, Murphy SE, Hecht SS, Hatsukami D, et al. (2008) Smokers with the CHRNA lung cancer-associated variants are exposed to higher levels of nicotine equivalents and a carcinogenic tobacco-specific nitrosamine. Cancer Res 68: 9137-9140.

107. Thorgeirsson TE, Geller F, Sulem P, Rafnar T, Wiste A, et al. (2008) A variant associated with nicotine dependence, lung cancer and peripheral arterial disease. Nature 452: 638-642.

108. Keskitalo K, Broms U, Heliövaara M, Ripatti S, Surakka I, et al. (2009) Association of serum cotinine level with a cluster of three nicotinic acetylcholine receptor genes (CHRNA3/CHRNA5/CHRNB4) on chromosome 15. Hum Mol Genet 18: 4007-4012.

109. Bierut LJ (2010) Convergence of genetic findings for nicotine dependence and smoking related diseases with chromosome 15q24-25. Trends Pharmacol Sci 31: 46-51.

110. Munafò MR, Timofeeva MN, Morris RW, Prieto-Merino D, Sattar N, et al. (2012) Association between genetic variants on chromosome 15q25 locus and objective measures of tobacco exposure. J Natl Cancer Inst 104: 740-748.

111. Bousman CA, Rivard C, Haese JD, Ambrosone C, Hyland A (2012) Alpha-5 and -3 nicotinic receptor gene variants predict nicotine 
dependence but not cessation: findings from the COMMIT cohort. Am J Med Genet B Neuropsychiatr Genet 159B: 227-235.

112. Ware JJ, van den Bree MB, Munafò MR (2011) Association of the CHRNA5-A3-B4 gene cluster with heaviness of smoking: a metaanalysis. Nicotine Tob Res 13: 1167-1175.

113. Ware JJ, van den Bree M, Munafò MR (2012) From men to mice: CHRNA5/CHRNA3, smoking behavior and disease. Nicotine Tob Res 14: 1291-1299.

114. Bierut LJ, Stitzel JA, Wang JC, Hinrichs AL, Grucza RA, et al. (2008) Variants in nicotinic receptors and risk for nicotine dependence. Am J Psychiatry 165: 1163-1171.

115. Liu JZ, Tozzi F, Waterworth DM, Pillai SG, Muglia P, et al. (2010) Metaanalysis and imputation refines the association of $15 \mathrm{q} 25$ with smoking quantity. Nat Genet 42: 436-440.

116. Chen LS, Saccone NL, Culverhouse RC, Bracci PM, Chen $\mathrm{CH}$, et al. (2012) Smoking and genetic risk variation across populations of European, Asian, and African American ancestry--a meta-analysis of chromosome 15q25. Genet Epidemiol 36: 340-351.

117. Tobacco and Genetics Consortium1 (2010) Genome-wide meta-analyses identify multiple loci associated with smoking behavior. Nat Genet 42: 441-447.

118. Breetvelt EJ, Numans ME, Aukes MF, Hoeben W, Strengman E, et al. (2012) The association of the alpha-5 subunit of the nicotinic acetylcholine receptor gene and the brain-derived neurotrophic factor gene with different aspects of smoking behavior. Psychiatr Genet 22 96-98.

119. Lips EH, Gaborieau V, McKay JD, Chabrier A, Hung RJ, et al. (2010) Association between a $15 \mathrm{q} 25$ gene variant, smoking quantity and tobacco-related cancers among 17000 individuals. Int J Epidemiol 39: 563-577.

120. Saccone NL, Wang JC, Breslau N, Johnson EO, Hatsukami D, et al. (2009) The CHRNA5-CHRNA3-CHRNB4 nicotinic receptor subunit gene cluster affects risk for nicotine dependence in African-Americans and in European-Americans. Cancer Res 69: 6848-6856.

121. Conlon MS, Bewick MA (2011) Single nucleotide polymorphisms in CHRNA5 rs16969968, CHRNA3 rs578776, and LOC123688 rs8034191 are associated with heaviness of smoking in women in Northeastern Ontario, Canada. Nicotine Tob Res 13: 1076-1083.

122. Robinson JD, Versace F, Lam CY, Minnix JA, Engelmann JM, et al. (2013) The CHRNA3 rs578776 Variant is Associated with an Intrinsic Reward Sensitivity Deficit in Smokers. Front Psychiatry 4: 114.

123. Nees F, Witt SH, Lourdusamy A, Vollstädt-Klein S, Steiner S, et al. (2013) Genetic risk for nicotine dependence in the cholinergic system and activation of the brain reward system in healthy adolescents. Neuropsychopharmacology 38: 2081-2089.

124. Sarginson JE, Killen JD, Lazzeroni LC, Fortmann SP, Ryan HS, et al. (2011) Markers in the 15q24 nicotinic receptor subunit gene cluster (CHRNA5-A3-B4) predict severity of nicotine addiction and response to smoking cessation therapy. Am J Med Genet B Neuropsychiatr Genet 156B: 275-284

125. Haller G, Druley T, Vallania FL, Mitra RD, Li P, et al. (2012) Rare missense variants in CHRNB4 are associated with reduced risk of nicotine dependence. Hum Mol Genet 21: 647-655.

126. Slimak MA, Ables JL, Frahm S, Antolin-Fontes B, Santos-Torres J, et al. (2014) Habenular expression of rare missense variants of the $B 4$ nicotinic receptor subunit alters nicotine consumption. Front Human Neurosci 8: article12.

127. Saccone NL, Schwantes-An TH, Wang JC, Grucza RA, Breslau N, et al. (2010) Multiple cholinergic nicotinic receptor genes affect nicotine dependence risk in African and European Americans. Genes Brain Behav 9: 741-750.

128. Thorgeirsson TE, Gudbjartsson DF, Surakka I, Vink JM, Amin N, et al. (2010) Sequence variants at CHRNB3-CHRNA6 and CYP2A6 affect smoking behavior. Nat Genet 42: 448-453.

129. Culverhouse RC, Johnson EO, Breslau N, Hatsukami DK, Sadler B, et al. (2014) Multiple distinct CHRNB3-CHRNA6 variants are genetic risk factors for nicotine dependence in African Americans and European Americans. Addiction 109: 814-822.

130. Bierut LJ, Madden PA, Breslau N, Johnson EO, Hatsukami D, et al. (2007) Novel genes identified in a high-density genome wide association study for nicotine dependence. Hum Mol Genet 16: 24-35.

131. Feng Y, Niu T, Xing H, Xu X, Chen C, et al. (2004) A common haplotype of the nicotine acetylcholine receptor alpha 4 subunit gene is associated with vulnerability to nicotine addiction in men. Am J Hum Genet 75 : $112-121$.

132. Xie P, Kranzler HR, Krauthammer M, Cosgrove KP, Oslin D, et al. (2011) Rare nonsynonymous variants in alpha-4 nicotinic acetylcholine receptor gene protect against nicotine dependence. Biol Psychiatry 70: 528-536

133. Li MD, Beuten J, Ma JZ, Payne TJ, Lou XY, et al. (2005) Ethnic- and gender-specific association of the nicotinic acetylcholine receptor alpha4 subunit gene (CHRNA4) with nicotine dependence. Hum Mol Genet 14 1211-1219.

134. Hutchison KE, Allen DL, Filbey FM, Jepson C, Lerman C, et al. (2007) CHRNA4 and tobacco dependence: from gene regulation to treatment outcome. Arch Gen Psychiatry 64: 1078-1086.

135. Wei J, Chu C, Wang Y, Yang Y, Wang Q, et al. (2012) Association study of 45 candidate genes in nicotine dependence in Han Chinese. Addict Behav 37: 622-626.

136. Kamens HM, Corley RP, McQueen MB, Stallings MC, Hopfer CJ, et al. (2013) Nominal association with CHRNA4 variants and nicotine dependence. Genes Brain Behav 12: 297-304.

137. Ehringer MA, Clegg HV, Collins AC, Corley RP, Crowley T, et al. (2007) Association of the neuronal nicotinic receptor beta2 subunit gene (CHRNB2) with subjective responses to alcohol and nicotine. Am J Med Genet B Neuropsychiatr Genet 144B: 596-604.

138. Hoft NR, Stitzel JA, Hutchison KE, Ehringer MA (2011) CHRNB2 promoter region: association with subjective effects to nicotine and gene expression differences. Genes Brain Behav 10: 176-185.

139. Nemoda Z, Szekely A, Sasvari-Szekely M (2011) Psychopathological aspects of dopaminergic gene polymorphisms in adolescence and young adulthood. Neurosci Biobehav Rev 35: 1665-1686.

140. Ho MK, Tyndale RF (2007) Overview of the pharmacogenomics of cigarette smoking. Pharmacogenomics J 7: 81-98.

141. Zhang Y, Bertolino A, Fazio L, Blasi G, Rampino A, et al. (2007) Polymorphisms in human dopamine D2 receptor gene affect gene expression, splicing, and neuronal activity during working memory. Proc Natl Acad Sci U S A 104: 20552-20557.

142. Ohmoto M, Sakaishi K, Hama A, Morita A, Nomura M, et al. (2013) Association between dopamine receptor 2 TaqIA polymorphisms and smoking behavior with an influence of ethnicity: a systematic review and meta-analysis update. Nicotine Tob Res 15: 633-642.

143. Stapleton JA, Sutherland G, O'Gara C, Spirling LI, Ball D (2011) Association between DRD2/ANKK1 Taq1A genotypes, depression and smoking cessation with nicotine replacement therapy. Pharmacogenet Genomics 21: 447-453.

144. Voisey J, Swagell CD, Hughes IP, van Daal A, Noble EP, et al. (2012) A DRD2 and ANKK1 haplotype is associated with nicotine dependence. Psychiatry Res 196: 285-289.

145. Munafò MR, Timpson NJ, David SP, Ebrahim S, Lawlor DA (2009) Association of the DRD2 gene Taq1A polymorphism and smoking behavior: a meta-analysis and new data. Nicotine Tob Res 11: 64-76.

146. Arinami T, Gao M, Hamaguchi H, Toru M (1997) A functional polymorphism in the promoter region of the dopamine $\mathrm{D} 2$ receptor gene is associated with schizophrenia. Hum Mol Genet 6: 577-582.

147. Asghari V, Sanyal S, Buchwaldt S, Paterson A, Jovanovic V, et al. (1995) Modulation of intracellular cyclic AMP levels by different human dopamine D4 receptor variants. J Neurochem 65: 1157-1165.

148. Oak JN, Oldenhof J, Van Tol HH (2000) The dopamine D(4) receptor: one decade of research. Eur J Pharmacol 405: 303-327.

149. Schoots O, Van Tol HH (2003) The human dopamine D4 receptor repeat sequences modulate expression. Pharmacogenomics J 3: 343-348. 
150. D'Souza UM, Russ C, Tahir E, Mill J, McGuffin P, et al. (2004) Functional effects of a tandem duplication polymorphism in the 5 'flanking region of the DRD4 gene. Biol Psychiatry 56: 691-697.

151. Okuyama Y, Ishiguro H, Toru M, Arinami T (1999) A genetic polymorphism in the promoter region of DRD4 associated with expression and schizophrenia. Biochem Biophys Res Commun 258: 292-295.

152. Kereszturi E, Kiraly O, Csapo Z, Tarnok Z, Gadoros J, et al. (2007) Association between the 120-bp duplication of the dopamine $\mathrm{D} 4$ receptor gene and attention deficit hyperactivity disorder: genetic and molecular analyses. Am J Med Genet B Neuropsychiatr Genet 144B: 231-236.

153. Vandenbergh DJ, Persico AM, Hawkins AL, Griffin CA, Li X, et al. (1992) Human dopamine transporter gene (DAT1) maps to chromosome 5p15.3 and displays a VNTR. Genomics 14: 1104-1106.

154. Franklin TR, Lohoff FW, Wang Z, Sciortino N, Harper D, et al. (2009) DAT genotype modulates brain and behavioral responses elicited by cigarette cues. Neuropsychopharmacology 34: 717-728.

155. Franklin TR, Wang Z, Li Y, Suh JJ, Goldman M, et al. (2011) Dopamine transporter genotype modulation of neural responses to smoking cues: confirmation in a new cohort. Addict Biol 16: 308-322.

156. Schmid B, Blomeyer D, Becker K, Treutlein J, Zimmermann US, et al. (2009) The interaction between the dopamine transporter gene and age at onset in relation to tobacco and alcohol use among 19-year-olds. Addict Biol 14: 489-499.

157. Ling D, Niu T, Feng Y, Xing H, Xu X (2004) Association between polymorphism of the dopamine transporter gene and early smoking onset: an interaction risk on nicotine dependence. J Hum Genet 49: 35-39.

158. Segman RH, Kanyas K, Karni O, Lerer E, Goltser-Dubner T, et al. (2007) Why do young women smoke? IV. Role of genetic variation in the dopamine transporter and lifetime traumatic experience. Am J Med Genet B Neuropsychiatr Genet 144B: 533-540.

159. Bergen AW, Conti DV, Van Den Berg D, Lee W, Liu J, et al. (2009) Dopamine genes and nicotine dependence in treatment-seeking and community smokers. Neuropsychopharmacology 34: 2252-2264.

160. Chen J, Lipska BK, Halim N, Ma QD, Matsumoto M, et al. (2004) Functional analysis of genetic variation in catechol-O-methyltransferase (COMT): effects on mRNA, protein, and enzyme activity in postmortem human brain. Am J Hum Genet 75: 807-821.

161. Ella E, Sato N, Nishizawa D, Kageyama S, Yamada H, et al. (2012) Association between dopamine beta hydroxylase rs5320 polymorphism and smoking behaviour in elderly Japanese. J Hum Genet 57: 385-390.

162. Gonzales D, Rennard SI, Nides M, Oncken, C, Azoulay S, et al (2006) Varenicline, an alpha4beta2 nicotinic acetylcholine receptor partial agonist, vs sustained release bupropion and placebo for smoking cessation: A randomized controlled trial. JAMA 296: 47-55.

163. Zhu S, Melcer T, Sun J, Rosbrook B, Pierce JP (2000) Smoking cessation with and without assistance: a population-based analysis. Am J Prev Med 18: 305-311.

164. Hughes JR (2009) How confident should we be that smoking cessation treatments work? Addiction 104: 1637-1640

165. Malaiyandi V, Lerman C, Benowitz NL, Jepson C, Patterson F, et al. (2006) Impact of CYP2A6 genotype on pretreatment smoking behaviour and nicotine levels from and usage of nicotine replacement therapy. Mol Psychiatry 11: 400-409.

166. Lerman C, Tyndale R, Patterson F, Wileyto EP, Shields PG, et al. (2006) Nicotine metabolite ratio predicts efficacy of transdermal nicotine for smoking cessation. Clin Pharmacol Ther 79: 600-608.

167. Schnoll RA, Patterson F (2009) Sex heterogeneity in pharmacogenetic smoking cessation clinical trials. Drug Alcohol Depend 104 Suppl 1: S94-99.

168. Sofuoglu M, Herman AI, Nadim H, Jatlow P (2012) Rapid nicotine clearance is associated with greater reward and heart rate increases from intravenous nicotine. Neuropsychopharmacology 37: 1509-1516.
169. Gu DF, Hinks LJ, Morton NE, Day IN (2000) The use of long PCR to confirm three common alleles at the CYP2A6 locus and the relationship between genotype and smoking habit. Ann Hum Genet 64: 383-390.

170. David SP, Johnstone EC, Churchman M, Aveyard P, Murphy MF, et al. (2011) Pharmacogenetics of smoking cessation in general practice: results from the patch II and patch in practice trials. Nicotine Tob Res 13: 157-167.

171. Johnstone EC, Elliot KM, David SP, Murphy MF, Walton RT, et al. (2007) Association of COMT Val108/158Met genotype with smoking cessation in a nicotine replacement therapy randomized trial. Cancer Epidemiol Biomarkers Prev 16: 1065-1069.

172. Sun H, Guo S, Chen D, Yang F, Zou Y, et al. (2012) Association of functional COMT Val108/Met polymorphism with smoking cessation in a nicotine replacement therapy. J Neural Transm 119: 1491-1498.

173. Chen LS, Baker TB, Piper ME, Breslau N, Cannon DS, et al. (2012) Interplay of genetic risk factors (CHRNA5-CHRNA3-CHRNB4) and cessation treatments in smoking cessation success. Am J Psychiatry 169: 735-742.

174. Munafò MR, Johnstone EC, Walther D, Uhl GR, Murphy MF, et al. (2011) CHRNA3 rs1051730 genotype and short-term smoking cessation. Nicotine Tob Res 13: 982-988.

175. Sarginson JE, Killen JD, Lazzeroni LC, Fortmann SP, Ryan HS, et al. (2011) Markers in the 15q24 nicotinic receptor subunit gene cluster (CHRNA5-A3-B4) predict severity of nicotine addiction and response to smoking cessation therapy. Am J Med Genet B Neuropsychiatr Genet 156B: $275-284$

176. Lerman C, Jepson EP, Wileyto PE, Epstein M, Rukstalis F, et al. (2006) Role of functional genetic variation in the dopamine D2 receptor (DRD2) in response to bupropion and nicotine replacement therapy for tobacco dependence: results of two randomized clinical trials. Neuropsychopharmacol 31: 231-242.

177. David SP, Munafò MR, Murphy MF, Proctor M, Walton RT, et al. (2008) Genetic variation in the dopamine D4 receptor (DRD4) gene and smoking cessation: follow-up of a randomised clinical trial of transdermal nicotine patch. Pharmacogenomics J 8: 122-128.

178. Xi ZX (2010) Preclinical Pharmacology, Efficacy and Safety of Varenicline in Smoking Cessation and Clinical Utility in High Risk Patients. Drug Healthc Patient Saf 2010: 39-48.

179. Gonzales D, Rennard SI, Nides M, Onchen C, Zaoulay S, et al. (2006) Varenicline, an a4ß2 nicotinic acetylcholine receptor partial agonist, vs sustained-release bupropion and placebo for smoking cessation. A randomized controlled trial. JAMA 291: 47-55.

180. Garrison GD, Dugan SE (2009) Varenicline: a first-line treatment option for smoking cessation. Clin Ther 31: 463-491.

181. Grassi MC, Enea D, Ferketich AK, Lu B, Pasquariello S, et al. (2011) Effectiveness of varenicline for smoking cessation: a 1-year follow-up study. J Subst Abuse Treat 41: 64-70.

182. King DP, Paciga S, Pickering E, Benowitz NL, Bierut LJ, et al. (2012) Smoking cessation pharmacogenetics: analysis of varenicline and bupropion in placebo-controlled clinical trials. Neuropsychopharmacology 37: 641-650.

183. Swan GE, Javitz HS, Jack LM, Wessel J, Michel M, et al. (2012) Varenicline for smoking cessation: nausea severity and variation in nicotinic receptor genes. Pharmacogenomics J 12: 349-358.

184. Singh S, Loke YK, Spangler JG, Furberg CD (2011) Risk of serious adverse cardiovascular events associated with varenicline: a systematic review and meta-analysis. CMAJ 183: 1359-1366.

185. Lerman C, Shields PG, Wileyto EP, Audrain J, Pinto A, et al. (2002) Pharmacogenetic investigation of smoking cessation treatment. Pharmacogenetics 12: 627-634.

186. Patterson F, Schnoll RA, Wileyto EP, Pinto A, Epstein LH, et al. (2008) Toward personalized therapy for smoking cessation: a randomized placebo-controlled trial of bupropion. Clin Pharmacol Ther 84: 320-325.

187. Uhl GR, Liu QR, Drgon T, Johnson C, Walther D, et al. (2008) Molecular genetics of successful smoking cessation: convergent genome-wide association study results. Arch Gen Psychiatry 65: 683-693. 
188. Conti DV, Lee W, Li D, Liu J, Van Den Berg D, et al. (2008) Nicotinic acetylcholine receptor beta2 subunit gene implicated in a systems-based candidate gene study of smoking cessation. Hum Mol Genet 17: 2834-2848.

189. Leventhal AM, David SP, Brightman M, Strong D, McGeary JE, et al. (2012) Dopamine D4 receptor gene variation moderates the efficacy of bupropion for smoking cessation. Pharmacogenomics J 12: 86-92.

190. O'Gara C, Stapleton J, Sutherland G, Guindalini C, Neale B, et al. (2007) Dopamine transporter polymorphisms are associated with short-term response to smoking cessation treatment. Pharmacogenet Genomics 17: 61-67.

191. Lerman C, Shields PG, Wileyto EP, Audrain J, Hawk LH Jr, et al. (2003) Effects of dopamine transporter and receptor polymorphisms on smoking cessation in a bupropion clinical trial. Health Psychol 22: 541-548.

192. Quaak M, van Schayck CP, Postma DS, Wagena EJ, van Schooten FJ (2012) Genetic variants in the serotonin transporter influence the efficacy of bupropion and nortriptyline in smoking cessation. Addiction 107: 178-187.

193. David SP, Munafò MR, Murphy MF, Walton RT, Johnstone EC (2007) The serotonin transporter 5-HTTLPR polymorphism and treatment response to nicotine patch: follow-up of a randomized controlled trial. Nicotine Tob Res 9: 225-231.

194. Munafò MR, Johnstone EC, Wileyto EP, Shields PG, Elliot KM, et al. (2006) Lack of association of 5-HTTLPR genotype with smoking cessation in a nicotine replacement therapy randomized trial. Cancer Epidemiol Biomarkers Prev 15: 398-400.

195. Mooney ME, Reus VI, Gorecki J, Hall SM, Humfleet GL, et al. (2008) Therapeutic drug monitoring of nortriptyline in smoking cessation: a multistudy analysis. Clin Pharmacol Ther 83: 436-442.

196. Bertilsson L, Dahl ML, Tybring G (1997) Pharmacogenetics of antidepressants: clinical aspects. Acta Psychiatr Scand Suppl 391: 14-21.

197. Gourlay SG, Stead LF, Benowitz NL (2004) Clonidine for smoking cessation. Cochrane Database Syst Rev 3: 1-12.

198. Cohen C, Kodas E, Griebel G (2005) CB1 receptor antagonists for the treatment of nicotine addiction. Pharmacol Biochem Behav 81: 387-395.

199. Castañé A, Valjent E, Ledent C, Parmentier M, Maldonado R, et al. (2002) Lack of CB1 cannabinoid receptors modifies nicotine behavioura responses, but not nicotine abstinence. Neuropharmacology 43: 857-867.

200. Wilcox CS, Noble EP, Oskooilar N (2011) ANKK1/DRD2 locus variants are associated with rimonabant efficacy in aiding smoking cessation: pilot data. J Investig Med 59: 1280-1283.

201. Lazary J, Juhasz G, Hunyady L, Bagdy G (2011) Personalized medicine can pave the way for the safe use of CBâ, receptor antagonists. Trends Pharmacol Sci 32: 270-280.

202. Beyer CE, Dwyer JM, Piesla MJ, Platt BJ, Shen R, et al. (2010) Depression-like phenotype following chronic CB1 receptor antagonism. Neurobiol Dis 39: 148-155.

203. Rose JE, Behm FM, Drgon T, Johnson C, Uhl GR (2010) Personalized smoking cessation: interactions between nicotine dose, dependence and quit-success genotype score. Mol Med 16: 247-253.

204. Heitjan DF, Asch DA, Ray R, Rukstalis M, Patterson F, et al. (2008) Costeffectiveness of pharmacogenetic testing to tailor smoking-cessation treatment. Pharmacogenomics J 8: 391-399.

205. McClure JB, Swan GE, St John J, Fauver R, Javitz HS, et al. (2013) Pharmacogenetic smoking cessation intervention in a health care setting: a pilot feasibility study. Nicotine Tob Res 15: 518-526.

206. Nakajima M, Kwon J-T, Tanaka N, Zenta T, Yamamoto Y, et al. (2001) Relationship between interindividual differences in nicotine metabolism and CYP2A6 genetic polymorphisms in humans. Clin Pharmacol Ther 68: $72-78$.

207. Kwon JT, Nakajima M, Chai S, Yom YK, Kim HK, et al. (2001) Nicotine metabolism and CYP2A6 allele frequencies in Koreans. Pharmacogenetics 11: 317-323.
208. Oscarson M, Gullstén H, Rautio A, Bernal ML, Sinues B, et al. (1998) Genotyping of human cytochrome P450 2A6 (CYP2A6), a nicotine Coxidase. FEBS Lett 438: 201-205.

209. Fernandez-Salguero P, Hoffman SMG, Cholerton S, Mohrenweiser H, Raunio H, et al. (1995) A genetic polymorphism in coumarin 7hydroxylation: Sequence of the human CYP2A genes and identification of variant CYP2A6 alleles. Am J Hum Genet 57: 651-660.

210. Oscarson M, McLellan RA, Gullstén H, Yue QY, Lang MA, et al. (1999) Characterisation and PCR-based detection of a CYP2A6 gene deletion found at a high frequency in a Chinese population. FEBS Lett 448: 105-110.

211. Nunoya KI, Yokoi T, Kimura K, Kainuma T, Satoh K, et al. (1999) A new CYP2A6 gene deletion responsible for the in vivo polymorphic metabolism of (+)-cis-3,5-dimethyl-2-(3-pyridyl)thiazolidin-4-one hydrochloride in humans. J Pharmacol Exp Ther 289: 437-442.

212. Nunoya K, Yokoi T, Kimura K, Inoue K, Kodama T, et al. (1998) A new deleted allele in the human cytochrome P450 2A6 (CYP2A6) gene found in individuals showing poor metabolic capacity to coumarin and $(+)$ cis-3,5-dimethyl-2-(3-pyridyl)thiazolidin-4-one hydrochloride (SM-12502). Pharmacogenetics 8: 239-249.

213. Ariyoshi N, Sekine H, Nakayama K, Saito K, Miyamoto A, et al. (2004) Identification of deletion-junction site of CYP $2 \mathrm{~A} 6^{*} 4 \mathrm{~B}$ allele lacking entire coding region of CYP2A6 in Japanese. Pharmacogenetics 14: 701-705.

214. Ariyoshi N, Sekine H, Saito K, Kamataki T (2002) Characterization of a genotype previously designated as CYP2A6 D-type: CYP2A $6{ }^{*} 4 \mathrm{~B}$, another entire gene deletion allele of the CYP2A6 gene in Japanese. Pharmacogenetics 12: 501-504.

215. Xu C, Rao YS, Xu B, Hoffmann E, Jones J, et al. (2002) An in vivo pilot study characterizing the new CYP $2 \mathrm{~A} 6{ }^{*} 7,{ }^{*} 8$, and ${ }^{*} 10$ alleles. Biochem Biophys Res Commun 290: 318-324.

216. Han S, Choi S, Chun YJ, Yun CH, Lee CH, et al. (2012) Functional characterization of allelic variants of polymorphic human cytochrome P450 $2 \mathrm{~A} 6\left(\mathrm{CYP} 2 \mathrm{~A} 6{ }^{\star} 5,{ }^{*} 7,{ }^{*} 8,{ }^{*} 18,{ }^{*} 19\right.$, and $\left.{ }^{*} 35\right)$. Biol Pharm Bull 35 : 394-399.

217. Yoshida R, Nakajima M, Nishimura K, Tokudome S, Kwon JT, et al. (2003) Effects of polymorphism in promoter region of human CYP2A6 gene $\left(\mathrm{CYP} 2 \mathrm{~A} 6^{*} 9\right)$ on expression level of messenger ribonucleic acid and enzymatic activity in vivo and in vitro. Clin Pharmacol Ther 74: 69-76.

218. Kiyotani K, Yamazaki H, Fujieda M, Iwano S, Matsumura K, et al. (2003) Decreased coumarin 7-hydroxylase activities and CYP2A6 expression levels in humans caused by genetic polymorphism in CYP2A6 promoter region $($ CYP2A6*9). Pharmacogenetics 13: 689-695.

219. Djordjevic N, Carrillo JA, Gervasini G, Jankovic S, Aklillu E (2010) In vivo evaluation of CYP2A6 and xanthine oxidase enzyme activities in the Serbian population. Eur J Clin Pharmacol 66: 571-578.

220. Yoshida R, Nakajima M, Watanabe Y, Kwon JT, Yokoi T (2002) Genetic polymorphisms in human CYP2A6 gene causing impaired nicotine metabolism. Br J Clin Pharmacol 54: 511-517.

221. Daigo S, Takahashi Y, Fujieda M, Ariyoshi N, Yamazaki H, et al. (2002) A novel mutant allele of the CYP2A6 gene (CYP2A $\left.6^{*} 11\right)$ found in a cancer patient who showed poor metabolic phenotype towards tegafur. Pharmacogenetics 12: 299-306.

222. Oscarson M, Ingelman-Sundberg M (2002) CYPalleles: a web page for nomenclature of human cytochrome P450 alleles. Drug Metab Pharmacokinet 17: 491-495.

223. Benowitz NL, Swan GE, Jacob P 3rd, Lessov-Schlaggar CN, Tyndale RF (2006) CYP2A6 genotype and the metabolism and disposition kinetics of nicotine. Clin Pharmacol Ther 80: 457-467.

224. Fukami T, Nakajima M, Higashi E, Yamanaka H, McLeod HL, et al. (2005b) A novel $\mathrm{CYP}^{2} \mathrm{~A}^{*} 20$ allele found in African-American population produces a truncated protein lacking enzymatic activity. Biochem Pharmacol 70: 801-808.

225. Tiong KH, Yiap BC, Tan EL, Ismail R, Ong CE (2010) Functional characterization of cytochrome P450 2 A6 allelic variants CYP2A6*15, 
Citation: Zdanowicz MM, Adams PW (2014) The Pharmacogenetics of Nicotine Dependence and Smoking Cessation Therapies. J Pharmacogenomics Pharmacoproteomics 5: 138. doi:10.4172/2153-0645.1000138

Page 20 of 20

CYP2A6*16, CYP2A6*2, and CYP2A6*22. Drug Metab Dispos 38: 745-751.

226. Al Koudsi N, Ahluwalia JS, Lin SK, Sellers EM, Tyndale RF (2009) A novel CYP2A6 allele (CYP2A6*35) resulting in an amino-acid substitution (Asn438Tyr) is associated with lower CYP2A6 activity in vivo. Pharmacogenomics J 9: 274-282. 